\title{
Nutrient transports in the Baltic Sea - results from a 30-year physical-biogeochemical reanalysis
}

\author{
Ye Liu ${ }^{1}$, H. E. Markus Meier ${ }^{2,1}$, and Kari Eilola ${ }^{1}$ \\ ${ }^{1}$ Swedish Meteorological and Hydrological Institute, Norrköping, Sweden \\ ${ }^{2}$ Leibniz Institute for Baltic Sea Research Warnemünde, Rostock, Germany \\ Correspondence to: Ye Liu (ye.liu@smhi.se)
}

Received: 19 July 2016 - Discussion started: 10 August 2016

Revised: 22 March 2017 - Accepted: 23 March 2017 - Published: 25 April 2017

\begin{abstract}
Long-term oxygen and nutrient transports in the Baltic Sea are reconstructed using the Swedish Coastal and Ocean Biogeochemical model (SCOBI) coupled to the Rossby Centre Ocean model (RCO). Two simulations with and without data assimilation covering the period 1970-1999 are carried out. Here, the "weakly coupled" scheme with the Ensemble Optimal Interpolation (EnOI) method is adopted to assimilate observed profiles in the reanalysis system. The reanalysis shows considerable improvement in the simulation of both oxygen and nutrient concentrations relative to the free run. Further, the results suggest that the assimilation of biogeochemical observations has a significant effect on the simulation of the oxygen-dependent dynamics of biogeochemical cycles. From the reanalysis, nutrient transports between sub-basins, between the coastal zone and the open sea, and across latitudinal and longitudinal cross sections are calculated. Further, the spatial distributions of regions with nutrient import or export are examined. Our results emphasize the important role of the Baltic proper for the entire Baltic Sea, with large net transport (export minus import) of nutrients from the Baltic proper into the surrounding sub-basins (except the net phosphorus import from the Gulf of Riga and the net nitrogen import from the Gulf of Riga and Danish Straits). In agreement with previous studies, we found that the Bothnian Sea imports large amounts of phosphorus from the Baltic proper that are retained in this sub-basin. For the calculation of sub-basin budgets, the location of the lateral borders of the sub-basins is crucial, because net transports may change sign with the location of the border. Although the overall transport patterns resemble the results of previous studies, our calculated estimates differ in detail considerably.
\end{abstract}

\section{Introduction}

The water exchange between the Baltic Sea and the North Sea is restricted by the narrows and sills in the Danish transition zone (Fig. 1). The hydrography of the Baltic Sea also depends on freshwater from rivers, which causes large salinity gradients between the surface layer and the saltier bottom layer and between the northern sub-basins and the entrance area (e.g., Meier and Kauker, 2003). The low-saline outflowing surface water is separated from high-saline inflowing bottom water by a transition layer, the halocline. The bottom water in the deep sub-basins is ventilated mainly by so-called Major Baltic Inflows (MBIs; Matthäus and Franck, 1992; Fischer and Matthäus, 1996). MBIs can significantly affect biogeochemical processes in the deep basins because of the inflow of large volumes of saline and oxygen-rich water into the Baltic Sea (e.g., Conley et al., 2009; Savchuk, 2010). In the Baltic Sea, the density stratification and long water residence time hamper the ventilation of deep waters. As a result, oxygen deficiency is a common feature. Additionally, nutrient loads from agriculture and other human activities of the large population in the catchment area increased nutrient concentrations in the water column. Actually, eutrophication has become a large environmental problem in the Baltic Sea in recent decades (e.g., Boesch et al., 2008; Pawlak et al., 2009; Wulff et al., 2001; Andersen et al., 2015). Therefore, accurate estimates of the ecological state and nutrient and water exchange between sub-basins and between the coastal zone and the open sea are of particular importance in managing the marine environment system.

On one hand, the estimation of biogeochemical processes, ecological state and nutrient exchange may rely on coupled 


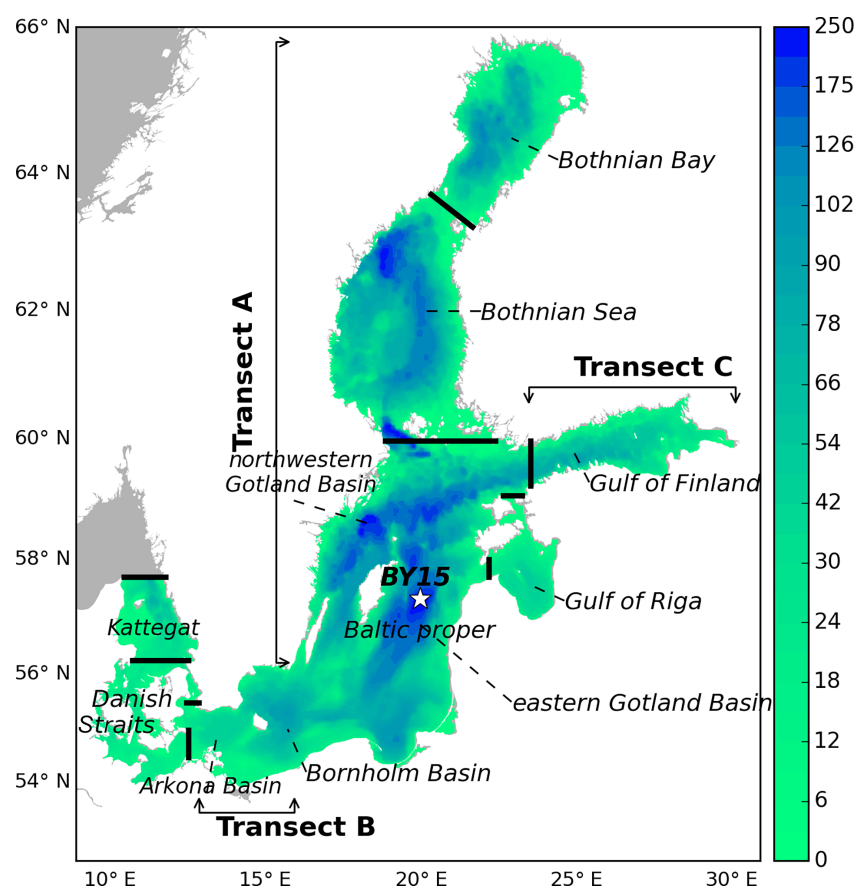

Figure 1. The bathymetry of the model (depth in $\mathrm{m}$ ). The border locations of sub-basins of the Baltic Sea used in this study are shown by the black lines, and the BY15 station is shown by the white star. The names of the sub-basins are Kattegat (KT), Danish Straits (DS), the Baltic proper (BP), the Gulf of Riga (GR), the Gulf of Finland (GF), the Bothnian Sea (BS), and the Bothnian Bay (BB).

marine ecosystem-circulation models (e.g., Neumann et al., 2002; Eilola et al., 2009, 2011; Almroth-Rosell et al., 2011, 2015; Maar et al., 2011; Daewel and Schrum, 2013). However, addressing biogeochemical cycles is a challenging task due to the complexity of the system. Obviously, there are large uncertainties in marine ecological simulations (e.g., Eilola et al., 2011). In contrast to the modeling of the physics of the atmosphere or ocean, where a basic description of the motion is provided by conservation equations, there is no basic set of equations that describe the marine ecosystem. Many biogeochemical processes are still poorly known and their uncertainties are difficult to quantify accurately. These potential sources of errors limit the applicability of the models both in forecasting and reanalysis. Further, imperfect initial conditions and model forcing also cause biases in the simulation results.

On the other hand, estimating nutrient budgets and transports between sub-basins may directly rely on observations and basin integrated budget models (Savchuk, 2005). The estimation accuracy depends on the spatial and temporal coverage of the measurements and the locations of borders between sub-basins. Although the data coverage in the Baltic Sea has gradually increased over time, the lack of observations still makes it difficult to estimate reliable biogeochemical cycles. Today, the availability of satellite sensor data like ocean color data from the OCTS (Ocean Color and Temperature Scanner) and from the SeaWiFS (Sea-viewing Wide Field-of-view Sensor) has provided the best spatial coverage of measurements. However, these sensors only give an estimate of a few biogeochemical parameters at the surface of the marine ecosystem and not the state of the entire marine ecosystem in the water column. Continuous observations of the deep ocean are only possible with in situ sensors, which have been deployed at only a limited number of stations (Claustre et al., 2010).

Given the coverage of observations and model deficiencies, we decided to perform a reanalysis based upon a highresolution, coupled physical-biogeochemical model to estimate the physical and biogeochemical state of the Baltic Sea. For this purpose, data assimilation continuously updates the model variables at the locations of the observations and in their neighborhood. Integration in time of the prognostic model equations allows the spread of the information from the observations within the model domain.

The assimilation of data into coupled physicalbiogeochemical models is confronted by various theoretical and practical challenges. For example, the response of the three-dimensional biogeochemical model to external forcing caused by the physical model is highly nonlinear. Further, it is difficult to use the biological observational information to reduce biases in the simulation of ocean physics which has an impact on modeled biogeochemistry (Béal et al., 2010). Besides, data assimilation as used in this study does not conserve mass, momentum and energy. Therefore, a reanalysis with data assimilation can never be dynamically fully consistent.

Nevertheless, the use of data assimilation complementing ecosystem modeling efforts has gained widespread attention (e.g., Hoteit et al., 2003, 2005; Allen et al., 2003; Natvik and Evensen, 2003; Triantafyllou et al., 2007, 2013; While et al., 2012; Teruzzi et al., 2014). Data assimilation into ecosystem models has focused both on parameter optimization and on state and flux estimations (Gregg et al., 2009). A comprehensive review of biological data assimilation experiments can be found in Gregg et al. (2009).

In the Baltic Sea, the biogeochemical data assimilation has started to become a research focus. For example, Liu et al. (2014) used the Ensemble Optimal Interpolation (EnOI) method to improve the multi-annual, high-resolution modeling of biogeochemical dynamics in the Baltic Sea. Fu (2016) analyzed the response of a coupled physical-biogeochemical model to the improved hydrodynamics in the Baltic Sea. Recently, several data assimilation studies have focused on the historical reanalysis of salinity and temperature in the Baltic Sea (e.g., Fu et al., 2012; Liu et al., 2013, 2014). Reanalysis has helped enormously in making the historical record of observed ocean parameters more homogeneous and useful for many purposes. For instance, ocean reanalysis data have been applied in research on ocean climate variability as well as on the variability of biogeochemistry and ecosystems (e.g., 
Bengtsson et al., 2004; Carton et al., 2005; Friedrichs et al., 2006). Ocean reanalysis can also be used for the validation of a wide range of model results (e.g., Fontana et al., 2013). For instance, the ocean mean state and circulation can be calculated from reanalysis results to evaluate regional climate ocean models (e.g., Meier et al., 2012). Moreover, reanalysis in the ocean is beneficial to the identification and correction of deficiencies in the observational records as well as for filling the gaps in observations. Regional and local model studies may use reanalysis results as initial and boundary conditions. A good reanalysis of biogeochemical state variables can dynamically describe indicators of eutrophication such as the long-term development of water nutrient pools.

The present paper focuses on the assimilation of profiles of temperature, salinity, nutrients and oxygen in the Baltic Sea following Liu et al. (2014). We aim to reproduce the ocean biogeochemical state with the help of information from both observations and a coupled physical-biogeochemical model for the period 1970-1999. Since 1970 the data coverage in the Baltic Sea is satisfactory. The results of the reanalysis are supposed to be used to estimate the water quality and ecological state with high spatial and temporal resolution in regions and during periods when no measurements are available. Further, nutrient transports across selected cross sections or between vertical layers are calculated with high resolution and accuracy, taking the complete dynamics of primitive equation models into account. This information cannot be obtained from either observations alone or from model results without data assimilation because the latter might have large biases in both space and time. We assess the nutrient budgets of the water column as well as of the nutrient exchanges between sub-basins and between the coastal zone and the open sea. The calculated budgets are compared to the results of other studies to evaluate our results. Hereby, we follow studies of other regions applying data assimilation for a biogeochemical reanalysis on long-term scales (Fontana et al., 2013; Ciavetta et al., 2016).

This paper is organized as follows. The physical and biogeochemical models are described in Sect. 2. Then the observational data set and the method of the reanalysis are introduced in Sects. 3 and 4, respectively. The experiment results, including comparisons with observations, are presented in Sect. 5. Finally, in Sects. 6 and 7, discussion and conclusions finalize the paper.

\section{Models}

The RCO (Rossby Centre Ocean) model is a Bryan-CoxSemtner primitive equation circulation model with a free surface (Killworth et al., 1991). Its open boundary conditions are implemented in northern Kattegat, based on prescribed sea level elevation at the lateral boundary (Stevens, 1991). An Orlanski radiation condition (Orlanski, 1976) is used to address the case of outflow, and the temperature and salinity variables are nudged toward climatologically annual mean profiles to deal with inflows (Meier et al., 2003). A Hiblertype dynamic-thermodynamic sea ice model (Hibler, 1979) with elastic-viscous-plastic rheology (Hunke and Dukowicz, 1997) and a two-equation turbulence closure scheme of the $k-\varepsilon$ type with flux boundary conditions (Meier, 2001) have been embedded into RCO. The deep-water mixing is assumed to be inversely proportional to the Brunt-Väisälä frequency, with the proportionality factor based on dissipation measurements in the eastern Gotland Basin (Lass et al., 2003). In its present version, RCO is used with a horizontal resolution of 2 nautical miles $(3.7 \mathrm{~km})$ and 83 vertical levels, with layer thicknesses of $3 \mathrm{~m}$. RCO allows direct communication between bottom boxes of the step-like topography (Beckmann and Döscher, 1997). A flux-corrected, monotonicity-preserving transport scheme is applied in RCO (Gerdes et al., 1991). RCO has no explicit horizontal diffusion. For further details of the model setup, the reader is referred to Meier et al. (2003) and Meier (2007).

The biogeochemical model called SCOBI (Swedish Coastal and Ocean Biogeochemical model) has been developed to study the biogeochemical nutrient cycling in the Baltic Sea (Marmefelt et al., 1999; Eilola et al., 2009; Almroth-Rosell et al., 2011, 2015). This model handles biological and ecological processes in the sea as well as sediment nutrient dynamics. SCOBI is coupled to RCO (e.g., Eilola et al., 2012, 2013, 2014). With the help of a simplified wave model, resuspension of organic matter is calculated from the wave and current-induced shear stresses (Almroth-Rosell et al., 2011). SCOBI has a constant carbon (C) to chlorophyll (Chl) ratio $\mathrm{C}: \mathrm{Chl}=50(\mathrm{mg} \mathrm{C}(\mathrm{mg}$ $\mathrm{Chl})^{-1}$ ), and the production of phytoplankton assimilates carbon $(\mathrm{C})$, nitrogen $(\mathrm{N})$ and phosphorus $(\mathrm{P})$ according to the Redfield molar ratio (C:N :P=106:16:1; Eilola et al., 2009). The molar ratio of a complete oxidation of the remineralized nutrients is $\mathrm{O}_{2}: \mathrm{C}=138$. For further details of the SCOBI model, the reader is referred to Eilola et al. (2009, 2011) and Almroth-Rosell et al. (2011).

RCO-SCOBI is forced by atmospheric forcing data calculated from regionalized ERA-40 data using the regional Rossby Centre Atmosphere (RCA) model (Samuelsson et al., 2011). The horizontal resolution of RCA is $25 \mathrm{~km}$. A bias correction method following Meier et al. (2011) is applied to the wind speed. Monthly mean river runoff observations (Bergström and Carlsson, 1994) are used for the hydrological forcing. Monthly nutrient loads are calculated from historical data (Savchuk et al., 2012).

\section{Observations}

The Baltic coastal shelf observation systems have been largely improved by the joint efforts of the countries surrounding the Baltic Sea. For example, the International Council for the Exploration of the Sea 

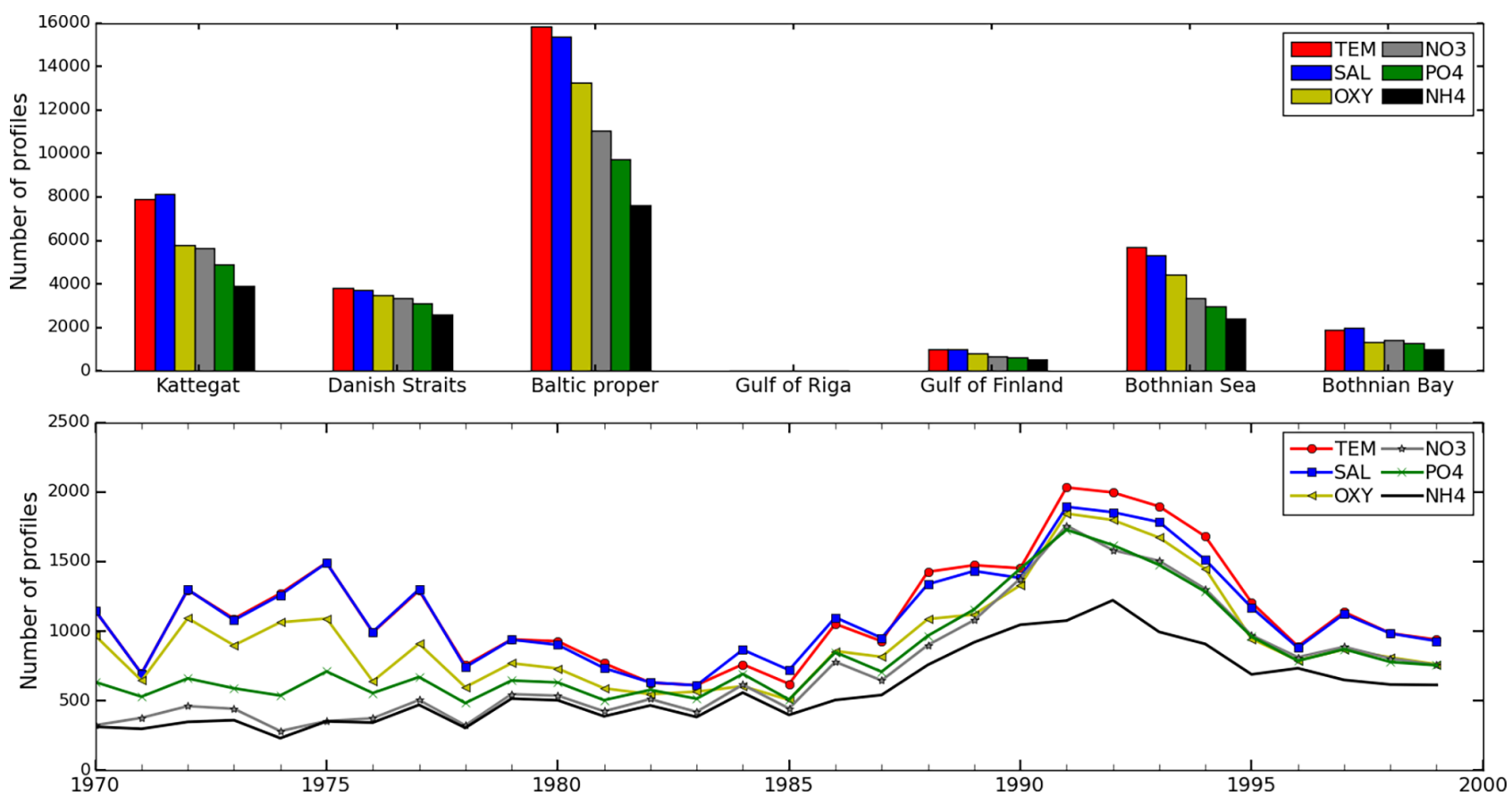

Figure 2. Number of observed profiles in different sub-basins (upper panel) and annual number of profiles from 1970-1999 (bottom panel).

(ICES; http://www.ices.dk) and the Swedish Ocean Archive (SHARK; http://sharkweb.smhi.se) are collecting the observations with the aim of monitoring the Baltic Sea. Furthermore, the Baltic Sea Operational Oceanographic System (BOOS; http://www.boos.org/) is providing near-realtime observations, and the publicly available database BED (Baltic Environmental Database; http://nest.su.se/bed) of the Baltic Nest Institute (BNI; http://www.balticnest.org) stores physical and environmental data from BNI partner institutes (see http://nest.su.se/bed/hydro_chem.shtml). Also the data of SHARK have been stored in BED. As a result, a comprehensive data set is collected for the Baltic Sea region. The assimilated observations in this study comprise both physical (temperature and salinity) and biogeochemical variables (oxygen, nitrate, phosphate and ammonium) from the SHARK database. Before assimilation, the data were quality controlled. These controls include checks of location and duplication and examination of differences between forecasts and observations. A profile was eliminated from the assimilation procedure when the station was located on land defined by the RCO bathymetry. We also removed observations when the difference between the model forecasting field and observations exceeds the given standard maximum deviation (for example $4.0 \mathrm{~mL} \mathrm{~L}^{-1}$ for oxygen concentration). We used an average of the observations in the same layer when there was more than one observation per layer. These observations cover almost the whole Baltic Sea including Kattegat and the Danish Straits. Figure 2 shows the number of biogeochemical observation profiles in different sub-basins and the temporal distribution of these biogeochemical observations. The number of observations is inhomogeneous in both temporal and spatial distribution over the period from 1970 to 1999. There are relatively more observations in the Baltic proper than in other sub-basins. In the Gulf of Riga, a minimum number of observation profiles ( 30 for oxygen, 30 for phosphate, 28 for nitrate and 28 for ammonium) is found. Obviously, the number of observations during the period of 19881994 is higher than that during other periods. Further, there are generally less observations from 1981 to 1983 than during other periods. The maximum number of observation profiles occurred in 1991 for oxygen (1844), phosphate (1728) and nitrate (1758). However, the number of ammonium observation profiles has a maximum value of 1222 in 1992. Moreover, compared to other variables the numbers of oxygen and ammonium observations are the largest and smallest, respectively. These observations from SHARK and BED are used to validate the model and assimilation results.

The simulated spatial variations of the late winter surface layer nutrient concentrations are compared with the spatial variations reconstructed from BED with the Data Assimilation System (DAS) by Sokolov et al. (1997). Due to insufficient historical data coverage, the average March fields were computed for time period 1995-2005 from over 3600 oceanographic stations found in BED. Also nutrient pools of dissolved inorganic nitrogen (DIN) and phosphorus (DIP) calculated with DAS (see Savchuk, 2010) are compared with the results of this study. See Eilola et al. (2011) for more details about the data handling by DAS. 


\section{Methodology and experimental setup}

Here we briefly describe the configuration of the data assimilation system of this study. We focus on the state estimation via EnOI. The distribution of stochastic errors are assumed to be Gaussian and non-biased. EnOI estimates an "optimal" oceanic state at a given time using observations, the numerical model and assumptions on their respective bias distribution. The relationship between them can be expressed as follows:

$\boldsymbol{\psi}^{a}=\boldsymbol{\psi}^{f}+\mathbf{K}\left(\boldsymbol{d}-\boldsymbol{H} \boldsymbol{\psi}^{f}\right)$,

$\mathbf{K}=\mathbf{P}^{f} \boldsymbol{H}^{T}\left(\boldsymbol{H} \mathbf{P}^{f} \boldsymbol{H}^{T}+(N-1) \mathbf{R}\right)^{-1}$,

where $\boldsymbol{d} \in \mathfrak{R}^{m}$ is the vector of observations with $m$ being the number of observations. $\boldsymbol{\psi} \in \mathfrak{R}^{n}$ is the $n$-dimensional model state vector which includes the sea level anomaly, temperature, salinity, oxygen, phosphate, ammonium and nitrate. The superscripts $a$ and $f$ refer to "analysis" and "forecast", respectively. $\mathbf{K} \in \Re^{n \times m}$ is the Kalman gain matrix, and $\boldsymbol{H}$ is an operator that maps the model state onto the observation space - often $\boldsymbol{H}$ is the linear interpolation. $\boldsymbol{d}-\boldsymbol{H} \boldsymbol{\psi}^{f} \in \mathfrak{R}^{m}$ is the innovation which is calculated in the observation space. $\mathbf{R} \in \mathfrak{R}^{m \times m}$ is the observation error covariance. $N$ is the number of the ensemble samples. EnOI computes the background error covariance (BEC) matrix $\mathbf{P} \in \Re^{n \times n}$, which determines how to spread out information from observations in space and between variables, by the ensemble perturbation matrix $\mathbf{A}^{\prime}=\mathbf{A}-\overline{\mathbf{A}}$ as follows:

$\mathbf{P}=\frac{\alpha}{N-1} \mathbf{A}^{\prime}\left(\mathbf{A}^{\prime}\right)^{T}$.

Here $\mathbf{A}=\left(\boldsymbol{\psi}_{1}, \boldsymbol{\psi}_{2} \ldots, \boldsymbol{\psi}_{N}\right) \in \mathfrak{R}^{n \times N}$ is the sample ensemble and $\overline{\mathbf{A}}=\frac{1}{N} \sum_{i=1}^{N} \boldsymbol{\psi}_{i}$ is the sample ensemble mean. The subscript $\mathrm{T}$ denotes the transpose of a matrix, and the scaling factor $\alpha \in(0,1)$ is introduced to tune the variance of the sample ensemble perturbations to a realistic level in order to capture the variability of model parameters like temperature and dissolved oxygen, which is dominated by misplacement of mesoscale features and which varies in location and intensity seasonally. Therefore, we hypothesize that the background errors are proportional to the model variability on intraseasonal time scales. We selected the samples from model results of a hindcast simulation without data assimilation from one and a half months before and after the calendar date of the assimilation time during the period 1964-1968 (Liu et al., 2013). The snapshots during the period 1964-1968 have been stored every 3 days. From every year during the selected period 1964-1968, 20 snapshots have been selected. Hence, a total of $N=100$ model samples are adopted to obtain a quasi-stationary BEC matrix. The analyses by EnOI rely on the sample ensemble because the analysis increment is a linear combination of sample ensemble anomalies. Other "sophisticated" sample ensembles could be tested but this is beyond the scope of this study. An adaptive scaling factor was calculated to adapt to the instantaneous forecast error variance before each local analysis (Liu et al., 2013, 2014). Further, localization is used to remove unrealistic long-range correlations with a quasi-Gaussian function and a uniform horizontal correlation scale of $70 \mathrm{~km}$. As a result, the quality of fields obtained by data assimilation is determined by the coverage and quality of observations (She et al., 2007). Moreover, the assimilation frequency or window is another factor that affects the assimilation fields. They are directly related to how many observations are entering the assimilation cycling and how often the model initial condition is adjusted by data assimilation (Liu et al., 2013). Here, we select an assimilation window of 3 days and the assimilation frequency is once every 7 days in the reanalysis experiment. It means that all the observations in the 3 days before and after the assimilation time are selected to yield the "new" initial condition for the following simulation during the current assimilation cycle. When observations become available at a certain time, the optimal state variables are calculated by Eq. (1), which are used as new initial conditions for the next simulation cycle.

Based on the above configuration, two experiments from January 1970 to December 1999 have been carried out. One experiment is a simulation without data assimilation (FREE). The other simulation is constrained by observations using the "weakly coupled" assimilation scheme based upon the EnOI method following Liu et al. (2014) which was briefly described above (REANA). Both simulations, FREE and REANA, are initialized for January 1970. The initial conditions are taken from an earlier run with RCO-SCOBI. The observation error in REANA is defined according to Liu et al. (2014). However, in Liu et al. (2014), only a shorter assimilation experiment for a 10 -year period is presented, and so far the reliability of the assimilation scheme in multi-decadal simulations has not been shown. Following Liu et al. (2014), our REANA experiment assimilated both physical and biogeochemical observations. In this study, we focus mainly on nutrient transports derived from the reanalysis.

To assess the results with (REANA) and without (FREE) data assimilation, the overall monthly mean RMSDs (root mean square differences) of oxygen, nitrate, phosphate and ammonium were calculated relative to observations during the whole integration period. The overall monthly mean RMSD is calculated by the following formula:

$\operatorname{RMSD}=\frac{1}{N_{j}} \sum_{j=1}^{N_{j}} \sqrt{\frac{1}{N_{t}} \sum_{i=1}^{N_{t}}\left(\varepsilon_{t}^{i}\right)^{2}}$

where $N_{t}$ is the number of the observations at assimilation time $t$ and $N_{j}$ is the number of observation days of 1 month for one field for the entire Baltic Sea. $\varepsilon_{t}^{i}=x_{\mathrm{sim}}^{i}(t)-x_{\mathrm{obs}}^{i}(t)$ represents the difference between the model result $\left(x_{\mathrm{sim}}\right)$ and observation $\left(x_{\mathrm{obs}}\right)$ at time $t$ and at the $i$ th observation loca- 
tion. We calculated $\varepsilon_{t}$ only at the locations of the observations at the time $t$, which is calculated by mapping the model field onto the observation space. Here it should be noted that the RMSDs were calculated before the time of assimilation analysis, and the corresponding observations were not yet assimilated into RCO-SCOBI (Liu et al., 2014).

Based on the reanalyzed simulation, the annual mean DIN and DIP transports as well as DIP persistency are also calculated. These transports $\left(\mathrm{VA}_{\text {Trans }}\right)$ are vertically integrated from the sea floor to the sea surface at every horizontal position at every time step of the integration according to

$\mathrm{VA}_{\text {Trans }}=\sum_{k=1}^{N} C_{k} u_{k} \Delta z_{k}$,

where $C_{k}, u_{k}, \Delta z_{k}$ and $N$ are the field concentrations of DIN, DIP or organic phosphorus (OrgP); the current velocity in horizontal direction; vertical dimensions of a grid cell; and the number of wet grid cells in the water column, respectively. From the net transport vector field, both magnitude and streamlines are calculated.

The total nutrient budgets are calculated from the sum of inorganic and organic bioavailable nutrients. The combined nutrient supplies from land and from the atmosphere have been taken into account. Nitrogen fixation is not included in the external supplies. The sinks of the nutrient budgets are calculated from the supplies from land/atmosphere, import/export from other basins and the changes in pelagic nutrient pools during the period $(\operatorname{sink}=$ supply + importexport-pool change). By this definition the nitrogen sink includes nitrogen fixation and denitrification. The nutrient flows for the total budgets are integrated along the selected borders of sub-basins using Eq. (5). Annual nutrient flows are averaged for the period 1970-1999. The total amount of nutrients for every sub-basin is calculated from the integral of nutrient concentrations from phytoplankton, zooplankton, detritus and dissolved nutrient times the volume of the subbasin according to

Total $=\sum_{i=1}^{N_{i}} \sum_{j=1}^{N_{j}} \sum_{k=1}^{N_{k}} C_{i, j, k} \Delta x_{i, j} \Delta y_{i, j} \Delta z_{k}$,

where $C_{i, j, k}, \Delta x_{i, j}, \Delta y_{i, j}$ and $\Delta z_{k}$ are the field concentrations (including nutrients from phytoplankton, zooplankton, detritus and dissolved nutrients), the horizontal and vertical dimensions of a grid cell, respectively. $N_{i}, N_{j}$ and $N_{k}$ are the number of grid cells in longitudinal, latitudinal and vertical direction for every sub-basin, respectively. Net transports across sections of sub-basins are calculated from the difference between export and import (relevant for the results in Sect. 5.6 and 5.7).

\section{Results}

In the following sub-sections, we evaluate the impact of data assimilation on the long-term evolution of biases (Sect. 5.1) and on vertical (Sect. 5.2) and horizontal (Sect. 5.3) distributions of nutrient concentrations. For the evaluation of time series of simulated oxygen, nitrate, phosphate and ammonium concentrations, the reader is referred to Liu et al. (2014; Figs. 6 and 7). After the evaluation of the assimilation method, we focus on the analysis of nutrient transports in the Baltic Sea based upon our reanalysis data that we consider to be the best available data set for such an analysis. In particular, we analyze the horizontal circulation of nutrients (Sect. 5.4), the horizontal distribution of nutrient sources and sinks, the nutrient exchange between the coastal zone and the open sea (Sect. 5.5), and the nutrient budgets of sub-basins (Sect. 5.6).

\subsection{Temporal evolution of biases and pools}

The biases in both FREE and REANA have been calculated relative to observations for dissolved oxygen and inorganic nutrients using Eq. (4) (Fig. 3). Data assimilation has significantly reduced bias of the model simulation. Generally, the RMSDs of oxygen and nutrient concentrations in REANA are smaller than those of FREE. However, the degree of improvements differs among the variables. The RMSD of oxygen is mostly greater and smaller than $1.0 \mathrm{~mL} \mathrm{~L}^{-1}$ for FREE and REANA, respectively. The mean RMSD of oxygen during this period has been reduced by $59 \%$ (from 1.43 to $0.59 \mathrm{~mL} \mathrm{~L}^{-1}$ ). Similar improvements appear in nitrate and phosphate concentrations. The mean RMSDs of nitrate and phosphate in REANA were reduced by $46 \%$ (from 2.04 to $1.11 \mathrm{mmol} \mathrm{m}^{-3}$ ) and $78 \%$ (from 1.05 to $0.23 \mathrm{mmol} \mathrm{m}^{-3}$ ) relative to those in FREE, respectively. Furthermore, the variability of RMSD of phosphate in FREE is large during the first 10 years and decreases afterwards with time. However, the data assimilation cannot always improve the model results. For instance, although the mean RMSD of ammonium is reduced by $45 \%$ (from 1.15 to $0.63 \mathrm{mmol} \mathrm{m}^{-3}$ ), the ammonium concentrations in REANA become worse relative to those in FREE during some months. An example appears in February 1975 when the RMSD of the ammonium concentrations in REANA $\left(3.07 \mathrm{mmol} \mathrm{m}^{-3}\right)$ is greater than that in FREE $\left(2.75 \mathrm{mmol} \mathrm{m}^{-3}\right)$. These results are similar to the findings by Liu et al. (2014). However, here we show that even the 30-year-long assimilation is reliable and that the RMSD of phosphate concentration decreases even further with data assimilation continuing for more than 10 years.

Further, the annual averaged pelagic pools of simulated DIN and DIP in the Baltic proper are compared to the corresponding pools estimated from the BED data in the Baltic proper (Fig. 4). The maximum annual differences of DIN and DIP pools compared to BED have been reduced by 57.5 and $72.3 \%$, respectively, from 400 and $650 \mathrm{kt}$ in FREE (not 

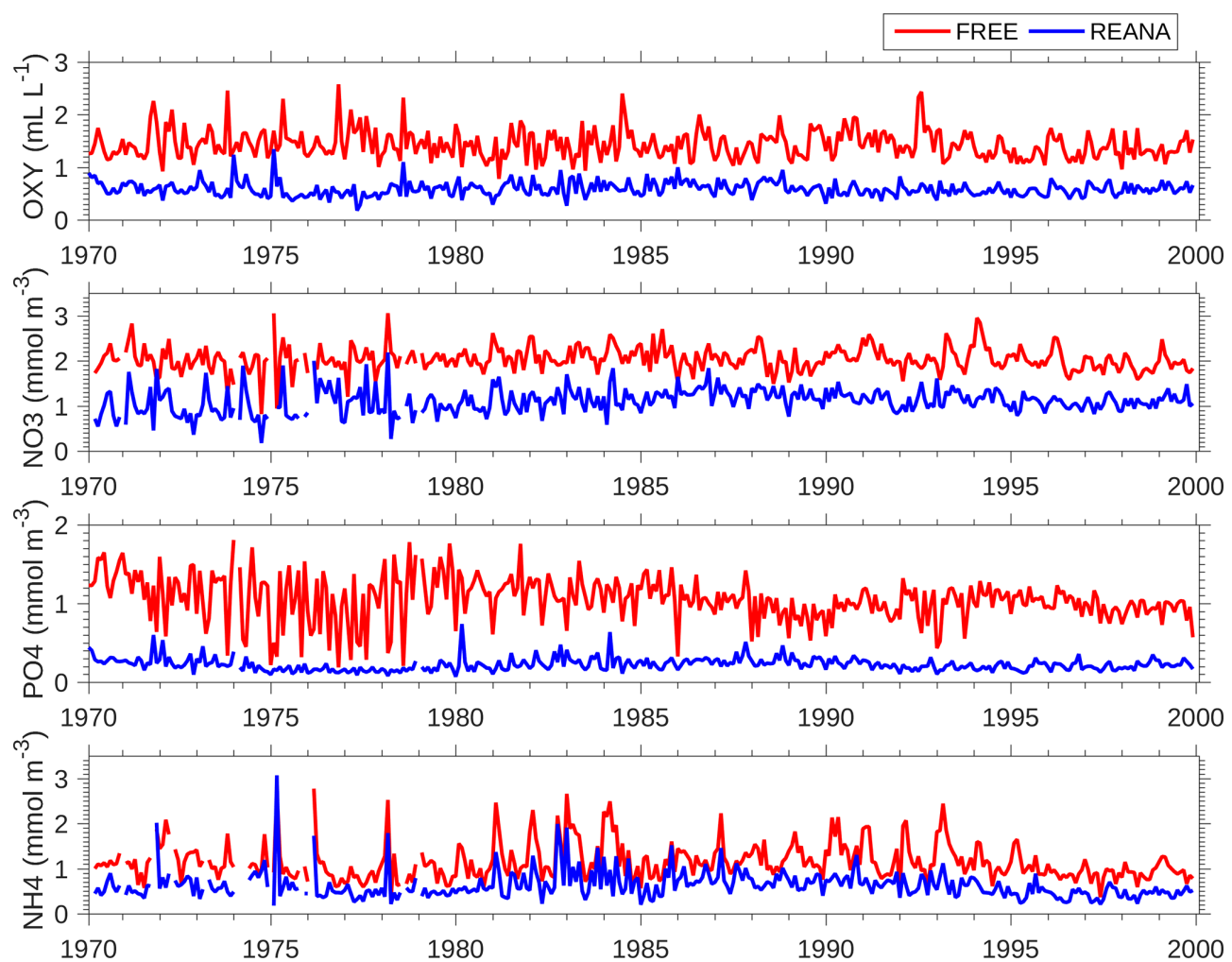

Figure 3. Monthly mean root mean square deviation (RMSD) between model results and observations for oxygen, nitrate, phosphate and ammonium in FREE (red) and REANA (blue).
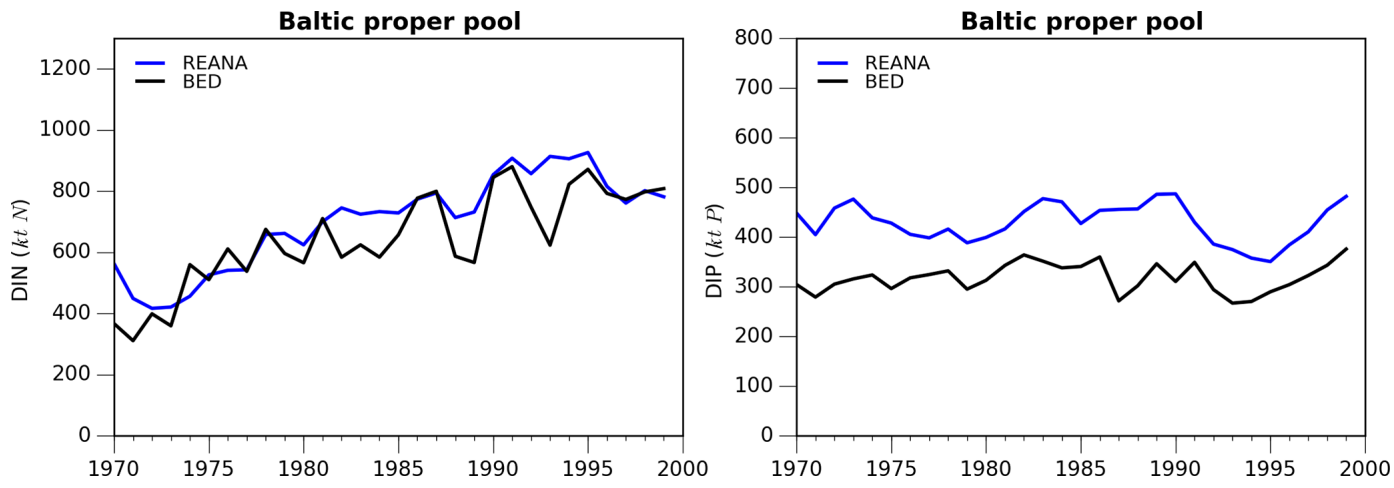

Figure 4. Annual mean integrated pools (in kt) of pelagic DIN and DIP in the Baltic proper calculated from REANA and from observations in BED.

shown) to 170 and $180 \mathrm{kt}$ in REANA. The remaining differences between REANA and BED may be explained by the methods of integration that differ. BED estimates are based on a limited amount of observations, while the model results are based on a large number of grid points with dynamically varying state variables. A similar result for hypoxic area was found by Väli et al. (2013). They showed with the help of model results which were sampled at the same times and locations of the observations that the applied interpolation algorithm underestimated the hypoxic area by about $40 \%$.

\subsection{Mean seasonal cycle of nutrients}

The long-term average seasonal cycles of temperature and inorganic nutrients at monitoring station BY15 at Gotland deep (for the location, see Fig. 1) give a hint of how data assimilation improves simulated nutrient dynamics in the Baltic proper (Fig. 5). The surface layer temperature and stratification show rapid increase from April to May, with concurrent rapid decrease of nutrient concentrations due to primary production down to $50-60 \mathrm{~m}$ depths. The cooling and increased vertical mixing in autumn and winter reduce tem- 

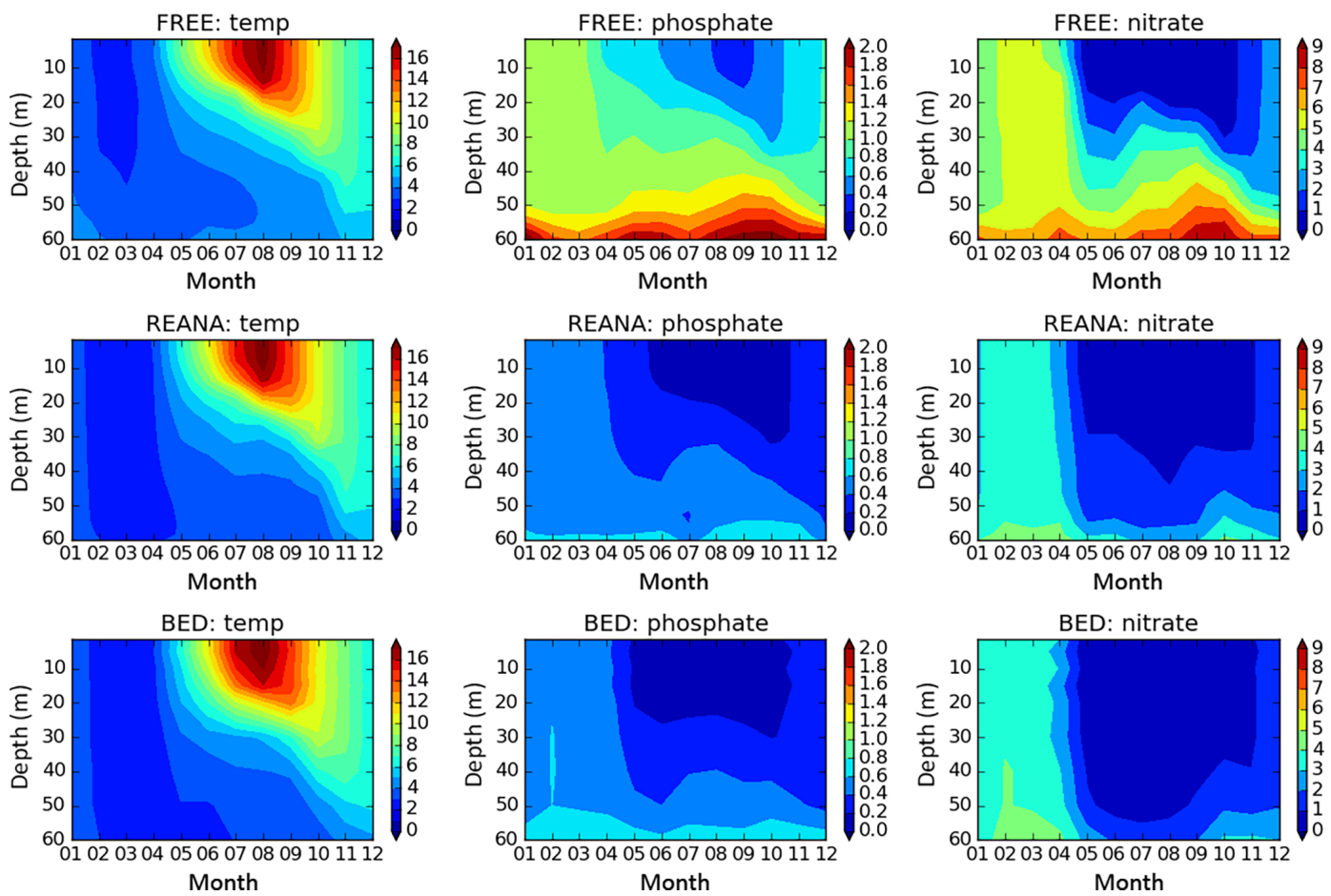

Figure 5. The seasonal cycle of monthly average (1970-1999) temperature $\left({ }^{\circ} \mathrm{C}\right)$, phosphate concentration $\left(\mathrm{mmol} \mathrm{m}^{-3}\right)$, and nitrate concentration $\left(\mathrm{mmol} \mathrm{m}^{-3}\right.$ ) at BY15 for FREE (row 1), REANA (row 2) and BED data (row 3), respectively.

peratures and bring nutrients from the deeper layers into the surface layers. RCO-SCOBI captures these variations. However, compared to BED, FREE has obvious biases, such as overestimated temperature stratification around a $30-50 \mathrm{~m}$ depth from late winter to early spring, higher concentration of nutrients at the $50-60 \mathrm{~m}$ depth, stronger vertical stratification of nutrient concentrations and less decrease of nutrients in the summer, especially below the thermocline, as well as also in the surface layers for phosphate. One reason for the biases is the vertical displacement of the halocline that is too shallow in RCO (e.g., Fig. 4 in Liu et al., 2014). The causes for the model bias in nutrient depletion below the summer thermocline are not known, but possible reasons are discussed by Eilola et al. (2011). These biases are significantly reduced in the reanalysis, which provides an improved description of vertical distributions of nutrients in the layers above the halocline.

\subsection{Spatial variations of late winter nutrient concentrations}

The average March concentrations (1970-1999) of DIP and DIN in the upper layers $(0-10 \mathrm{~m})$, as well as their ratio (DIN : DIP), were calculated (Fig. 6). Due to insufficient historical data the corresponding BED maps describe the averages for the period 1995-2005 as a basis for model-todata comparison. In BED results the highest concentration of DIP occurs in the Gulf of Riga and the Gulf of Finland.
Relatively high concentrations of DIP are found in the entire Gotland Basin. The DIP concentrations in the Bothnian Sea and Bothnian Bay are obviously lower than in other regions. Generally, the DIP in FREE has been largely overestimated in all regions relative to BED, especially in the Baltic proper. Further, in BED, high concentrations of DIN occur in coastal waters close to the river mouths of the major rivers in the southern Baltic proper. DIN concentrations in the Gulf of Finland and in the Gulf of Riga are also high and cover large areas of these gulfs. Unlike the BED data, the DIN in FREE also has high concentrations in the entire southern and eastern coastal zones of the Baltic proper. As a result, FREE shows a gradient in DIN concentrations between the coastal zone and the open sea in the entire southern Baltic proper. The DIN and DIP patterns result in high and low DIN : DIP ratios in the Bothnian Bay and Baltic proper, respectively. The highest DIN : DIP ratios are found in the Bothnian Bay in BED and in the Gulf of Riga in FREE. FREE has captured this large-scale pattern, but there are substantial regional differences. By the constraints of the observation information, REANA has improved the spatial distributions of DIN and DIP significantly compared to BED. In particular, DIP concentrations in REANA are much closer to the interpolated BED observations. 

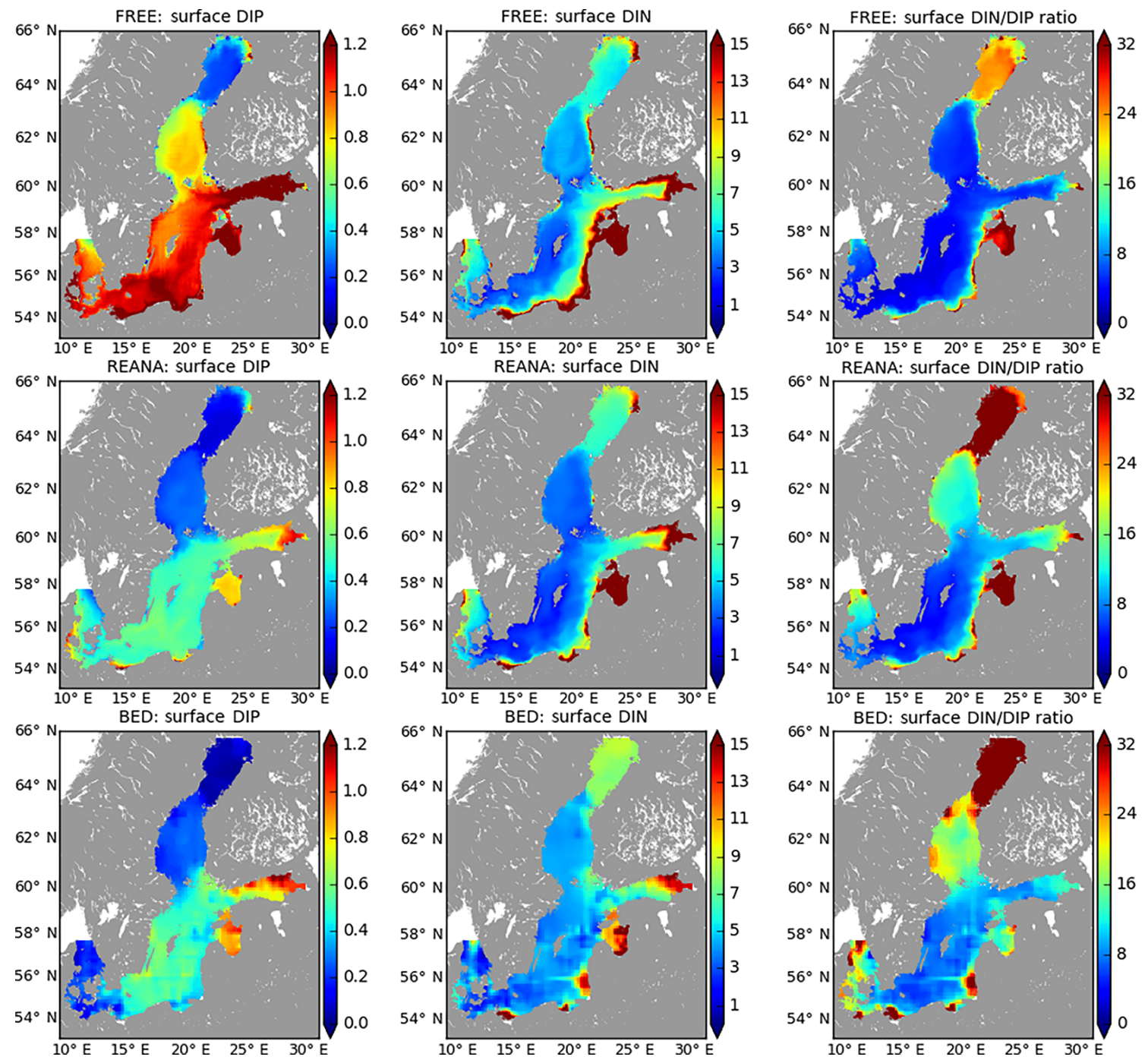

Figure 6. Simulated monthly (March) mean (1970-1999) surface layer (0-10 m) concentrations of DIP ( $\mathrm{mmol} \mathrm{m}^{-3}$; left), DIN (mmol m ${ }^{-3}$; middle), and the corresponding DIN to DIP ratio (right) from FREE and REANA are shown in rows 1 and 2, respectively. The corresponding BED maps in row 3 are calculated from observations monitored during the period 1995-2005.

\subsection{Mean horizontal circulation of nutrients}

Nutrient transport directly affects the biogeochemical cycles and the eutrophication of the Baltic Sea. The persistency of vertically integrated transports (Fig. 7) is defined, for instance, by Eilola et al. (2012). One should note that the results by Eilola et al. (2012) are based upon 30-year averages for the control period 1978-2007 of a downscaled climate scenario from a global circulation model. Similar calculations of transports will therefore be briefly presented in the present study, since the hindcast period is better represented when the model is forced by the assimilated atmospheric (ERA-40) and Baltic Sea data (REANA). DIP has the largest transports in the central parts of the Baltic proper, with high persistency because the volume transports are generally larger in deeper rather than in shallower areas. In the
Bornholm Basin and the eastern parts of the central Baltic proper, cyclonic circulation patterns are found. In the western parts of the central Baltic proper, southward transports prevail. Relatively large magnitudes of transports of DIP are also found in the northwestern Gotland Basin, in the southern Bornholm Basin, and through the Slupsk Channel connecting the Bornholm Basin and Gotland Basin. Similar transport patterns are also found for DIN, OrgP and OrgN (not shown). Compared to Eilola et al. (2012), DIN, DIP, OrgP and OrgN transports and their persistency are larger, although the overall patterns are similar. For example, in Eilola et al. (2012, their Fig. 1), large DIN transports appear in the southern Baltic proper and the Bornholm Basin. Similar differences are also found in both DIP and OrgP transports. 

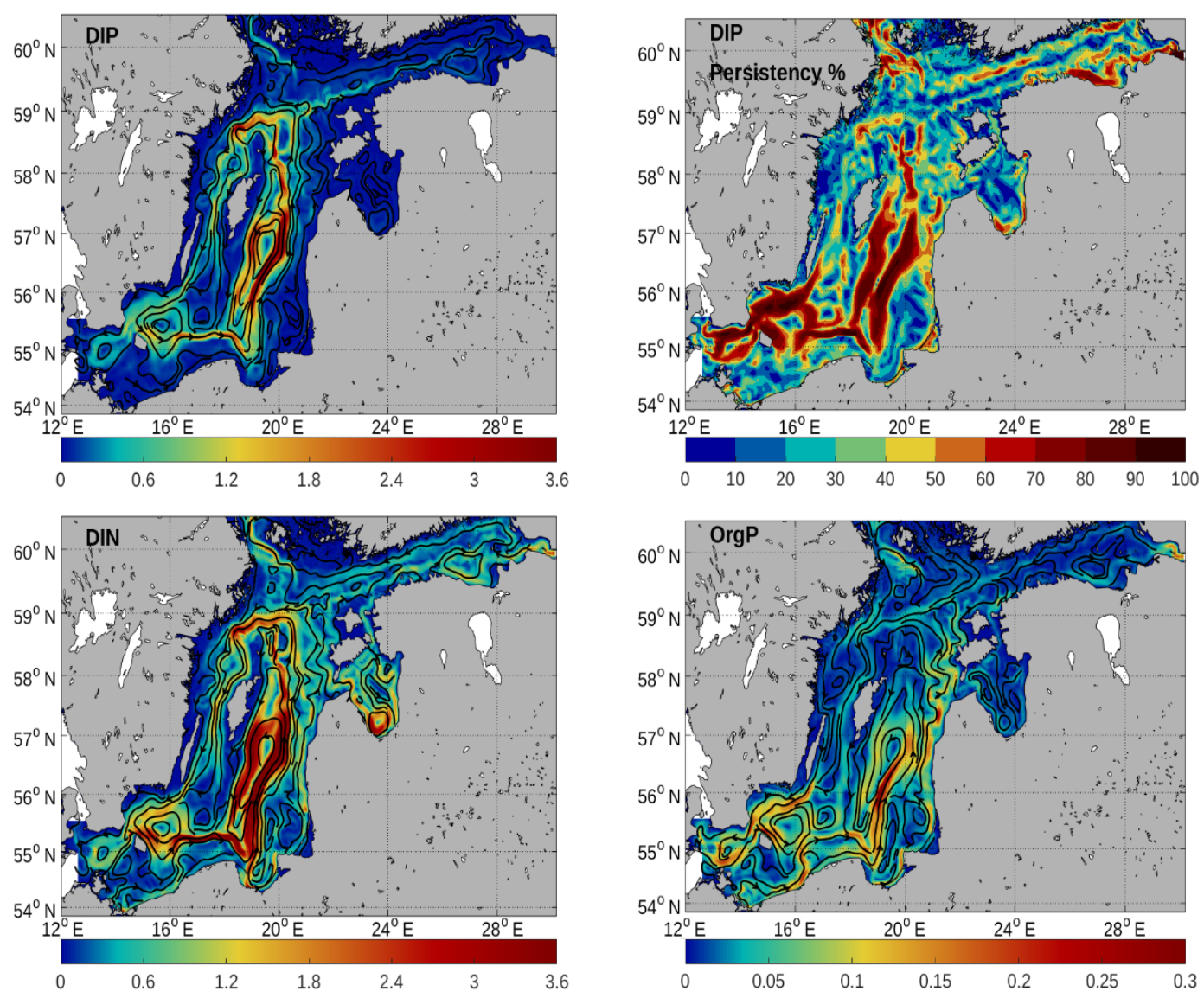

Figure 7. Annual mean DIP transports and the corresponding DIP persistency, DIN and OrgP transports for REANA averaged for the period 1970-1999. The black solid lines with arrows show the streamlines and direction of transports. The magnitude of transports (kt km $\left.{ }^{-1} \mathrm{yr}^{-1}\right)$ and the persistency $(\%)$ are shown by the background color. The corresponding values are shown in the colored bars.

\subsection{Internal nutrient sources and sinks}

The horizontal distributions of areas with internal sources and sinks of phosphorus and nitrogen are illustrated in Fig. 8. A net inflow (inflow $\geq$ outflow) of nutrients to each cell of the horizontal model grid is defined as a sink (import) and counted as positive, while a net outflow (inflow $\leq$ outflow) is defined as a source (export) and counted as negative (Eilola et al., 2012). Source areas of DIP generally coincide with sink areas of OrgP, and vice versa. This is also partly true for DIN and OrgN, but the sink for DIN has a large contribution from denitrification that transfers DIN to dissolved $\mathrm{N}_{2}$. The difference between phosphorus and nitrogen sources and sinks is oxygen dependent, because the removal of $\mathrm{N}$ is enhanced at lower oxygen concentrations, while the sediment phosphorus sink is weakened (e.g., Savchuk, 2010). Sediments may even temporarily become a source under anoxic conditions, when older mineral-bound $\mathrm{P}$ can be released to the overlying water. Source areas of DIN are mainly found in the Gulf of Riga and the deeper parts of the Arkona and Bornholm basins. The largest DIP sources occur in the eastern parts of the Gotland Basin as well as in the deepest parts of the Born- holm and Arkona basins, whereas the largest sink of OrgP occurs in the central Baltic proper. The main sources of DIP are generally found in regions where water depth is greater than $70 \mathrm{~m}$ (in other words below the permanent halocline in the Baltic proper), while the main sources of $\operatorname{OrgP}$ (and $\operatorname{OrgN}$ ) are found in the productive coastal areas shallower than about $30-40 \mathrm{~m}$ (see also Fig. 9). Indeed, DIP export is largest in areas with a water depth between 70 and $100 \mathrm{~m}$ and decreases towards greater water depths (Fig. 9).

According to the accumulated import of nutrients (Fig. 9), the magnitude of the DIP export is larger than that of the DIP import. This indicates that not all of the supply of phosphorus from land and atmosphere is retained within the Baltic proper as will be further discussed from the nutrient budgets in Sect. 5.6. For DIN, however, we may notice only a very small net export from the Baltic proper to adjacent subbasins, while for OrgP and OrgN, imports and exports are almost balanced (Fig. 9). The nitrogen and phosphorus supply from land is implemented in sea areas with a bottom depth usually of $6 \mathrm{~m}$. This is where the river mouths are located in the model. 

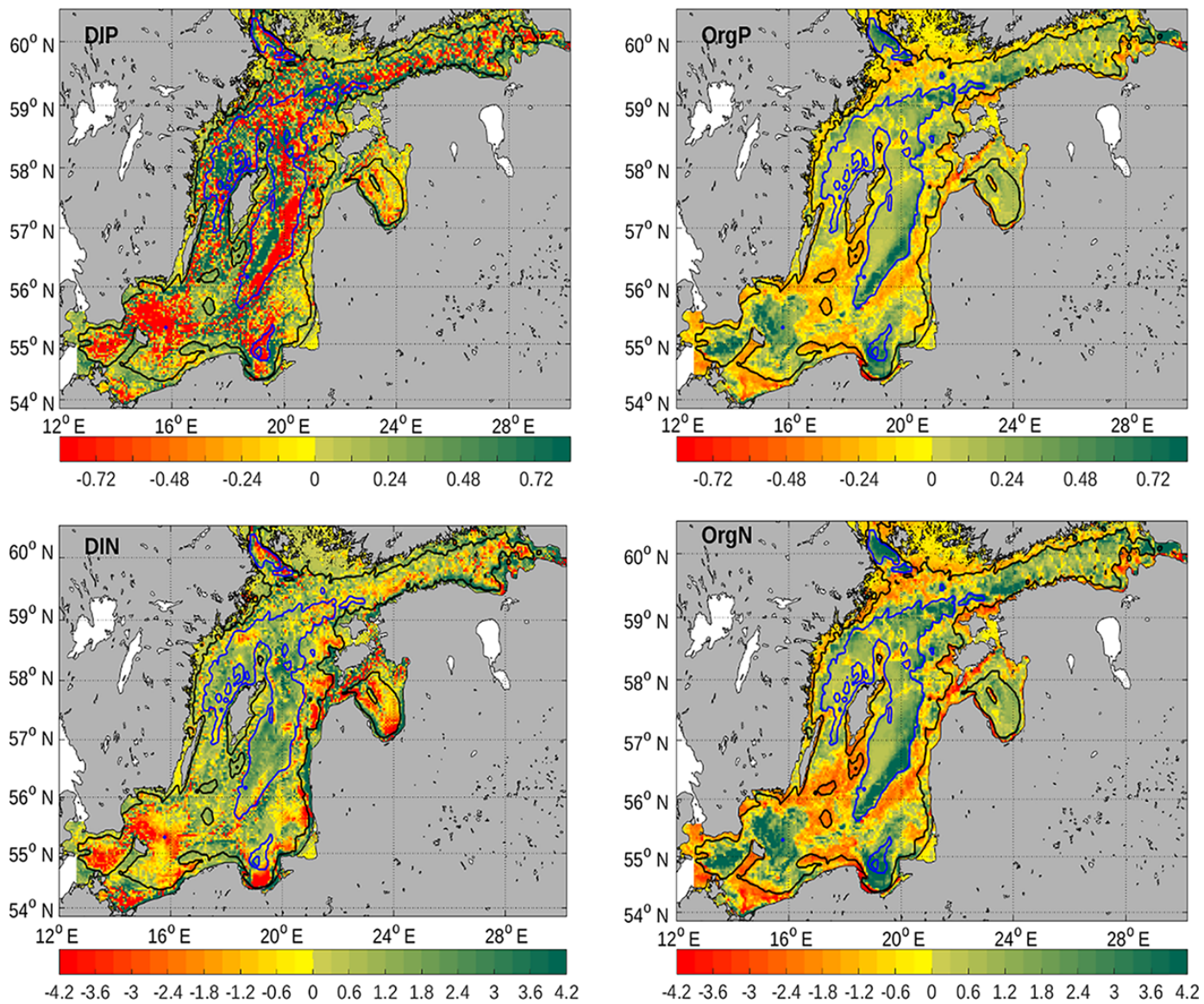

Figure 8. Spatial distributions of annual mean import of DIP, OrgP, DIN and OrgN averaged for the period 1970-1999. The magnitude of import and its corresponding value $\left(\mathrm{kt} \mathrm{km}^{-2} \mathrm{yr}^{-1}\right)$ are shown by the background color and color bar, respectively. Green colors denote positive values (import), and yellow to red colors denote negative values (export). The black and blue lines show 30 and $100 \mathrm{~m}$ depth contours of the model, respectively.

There is a large import of DIP to areas with a depth range between 40-70 $\mathrm{m}$ (Fig. 9). This import does not show a counterpart in the export of OrgP in Fig. 9. This result might be explained by local processes causing the phytoplankton uptake and sediment deposition of DIP. There is an import of DIN to these areas that together with nitrogen fixation and sediment-water fluxes of DIN may support local production of organic matter. The phosphorus sink may be partly caused by oxygen-dependent water-sediment fluxes that bind DIP to ironbound phosphorus in oxic sediments (Almroth-Rosell et al., 2015). This effect is not included in Eilola et al. (2012) but might potentially be accounted for by the adjusted DIP transports in REANA. The results of REANA indicate that there is an additional sink, but the relative importance of the different processes causing this sink (data assimilation or sediment processes) is, however, not possible to evaluate from the present reanalysis data set.

A partly opposite exchange profile is found for OrgP (Fig. 9). Coastal areas with a water depth of up to $40 \mathrm{~m}$ are exporting organic phosphorus, whereas deeper areas import
OrgP. Production in the coastal zone of the Baltic proper and sedimentation in the open sea is almost balanced.

The largest export of DIN occurs due to rivers in the very shallow coastal zone. The magnitude of DIN imports and exports in areas with greater water depths are much smaller. Obviously, DIN supplied from land is already consumed in the coastal zone (Voss et al., 2005; Almroth-Rosell et al., 2011), and, consequently, only a minor fraction of the nitrogen supplied to the shallow area can continuously reach regions deeper than $100 \mathrm{~m}$ (Eilola et al., 2012; Radtke et al., 2012).

\subsection{Nutrient budgets of sub-basins}

The Baltic Sea is divided into seven sub-basins according to the selected sections, which form the borders of the subbasins (Fig. 1). We calculate total nutrient budgets for each of the sub-basins from the reanalysis (Figs. 10 and 11). Changes in pools are calculated as differences between 1971 and 1999 because the initial adjustment process due to the assimilation is taking place during the first year (1970; not shown). 


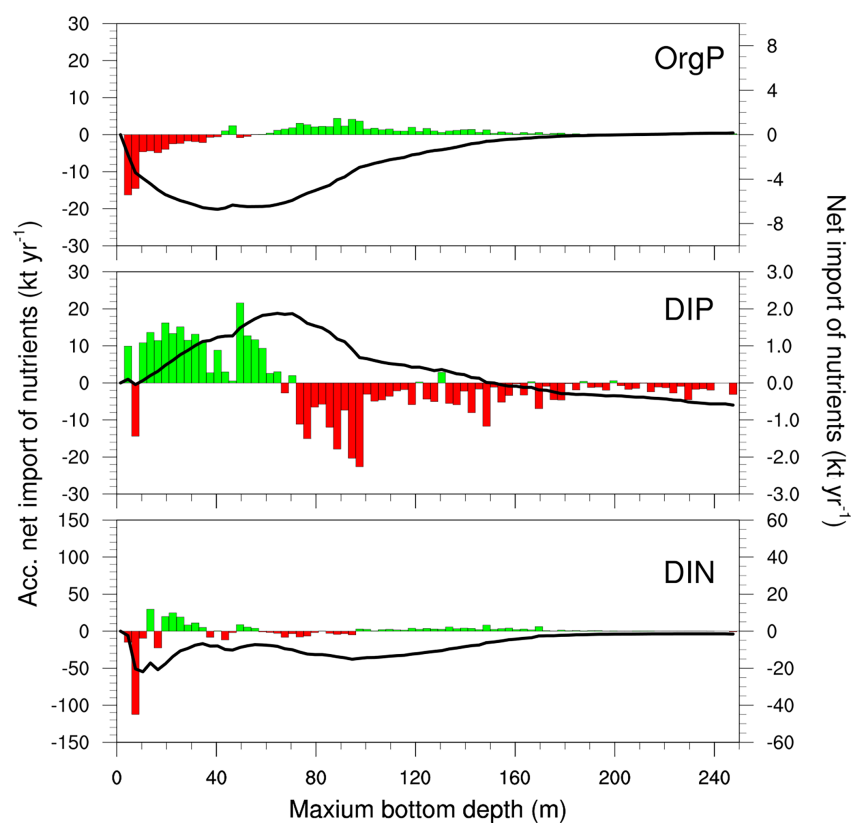

Figure 9. Annual mean, accumulated net imports (black lines), and imports of OrgP, DIP and DIN (color bars) to regions with the same depth in the Baltic proper averaged for the period 1970-1999.

The largest annual mean external phosphorus load occurs in the Baltic proper and amounts to $34.2 \mathrm{kt} \mathrm{yr}^{-1}$ (Fig. 10). In addition, in the Baltic proper the largest annual mean phosphorus sink of $25.0 \mathrm{kt} \mathrm{yr}^{-1}$ is also found. Whereas during the period 1971-1999 the phosphorus content in the Baltic proper increased, we found decreasing phosphorus content in the Gulf of Finland, Bothnian Bay, Bothnian Sea and Danish Straits. The largest export and import of phosphorus between sub-basins are found for the exchange between the Baltic proper and the Gulf of Finland, which amount to 24.3 and $22.5 \mathrm{kt} \mathrm{yr}^{-1}$, respectively. However, the largest net exchange (import minus export) appears between the Baltic proper and Bothnian Sea. It is also found that the Baltic proper exports more phosphorus to neighboring sub-basins than it imports, except for the Gulf of Riga. The annual mean net phosphorus exported from the Baltic proper into the Danish Straits, the Bothnian Sea, the Gulf of Finland and the Gulf of Riga during the period 1971-1999 amounts to 1.7, 3.6, 1.8 and $-0.6 \mathrm{kt} \mathrm{yr}^{-1}$, respectively. The exchange of phosphorus between the Baltic proper and the Gulf of Riga is smallest relative to the other three neighboring sub-basins. Further, we found that the net transport, import and export of phosphorus into the Bothnian Bay are the smallest relative to the other sub-basins.

Nitrogen transports between Baltic Sea sub-basins are different compared to phosphorus transports (Fig. 11). For example, the Baltic proper has larger nitrogen sinks than external sources. Further, during the period 1971-1999 the nitrogen content decreased in the Gulf of Riga and increased in

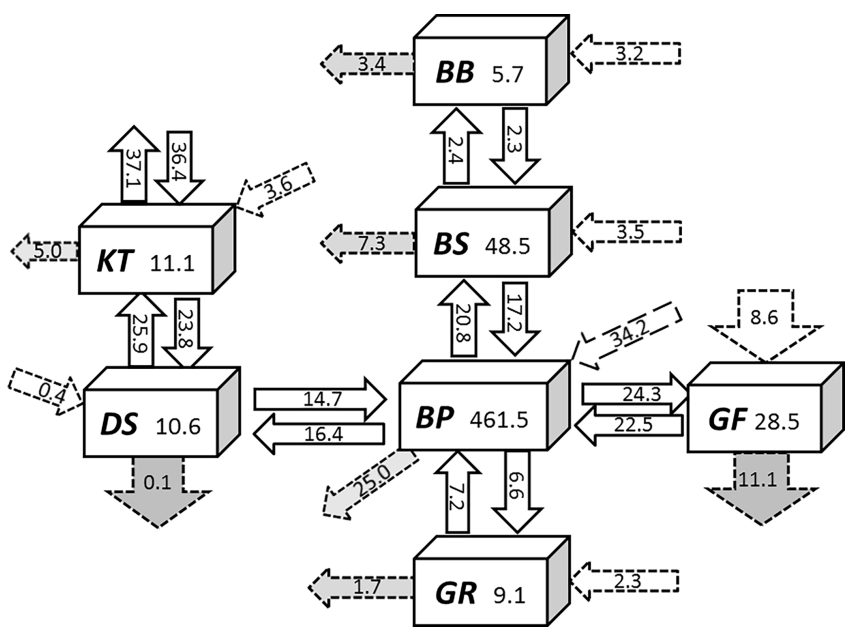

Figure 10. Annual mean total phosphorus budgets of the Baltic Sea averaged for the period 1971-1999. The average total amounts are in kt, and transport flows and sink/source fluxes (external nutrient inputs/sink) are in $\mathrm{kt} \mathrm{yr}^{-1}$. External nutrient inputs from atmosphere and land are combined.

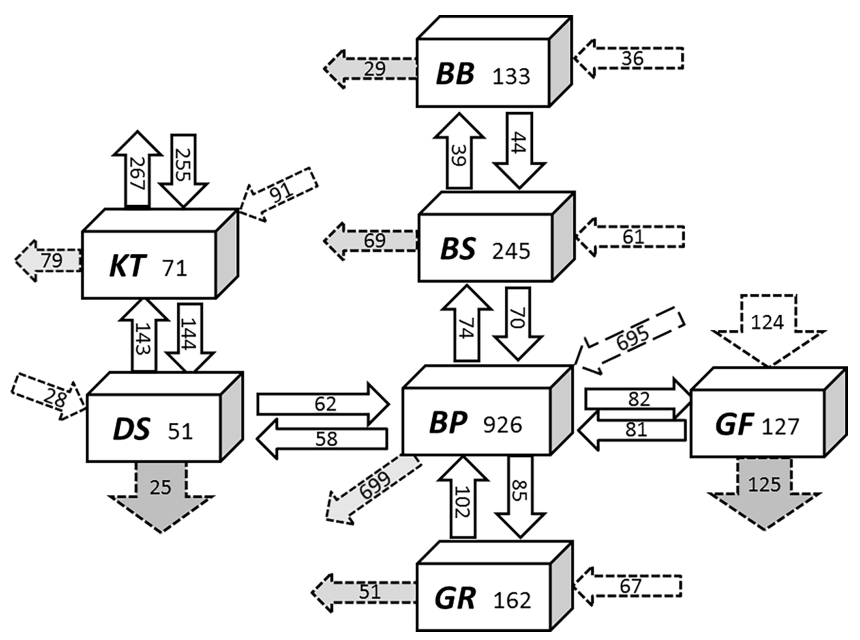

Figure 11. The same as Fig. 9, but for nitrogen.

the Bothnian Bay, respectively. In the Gulf of Finland and Danish Straits, the difference between the external supply and internal sink of nitrogen is equal to the net transport into the Gulf of Finland and Danish Straits. The large sink of nitrogen in the Bothnian Bay is noteworthy. We also found relatively large net transports of nitrogen from the Gulf of Riga into the Baltic proper. This is mainly explained by the relatively high nitrate concentrations in the Gulf of Riga relative to other sub-basins.

The 3-D nutrient pools constructed by data assimilation methods offer an opportunity to evaluate with improved estimates the changes in Baltic Sea eutrophication. As an example, an investigation of the trophic state from changes in 5 -year average nutrient pools in REANA shows that the to- 

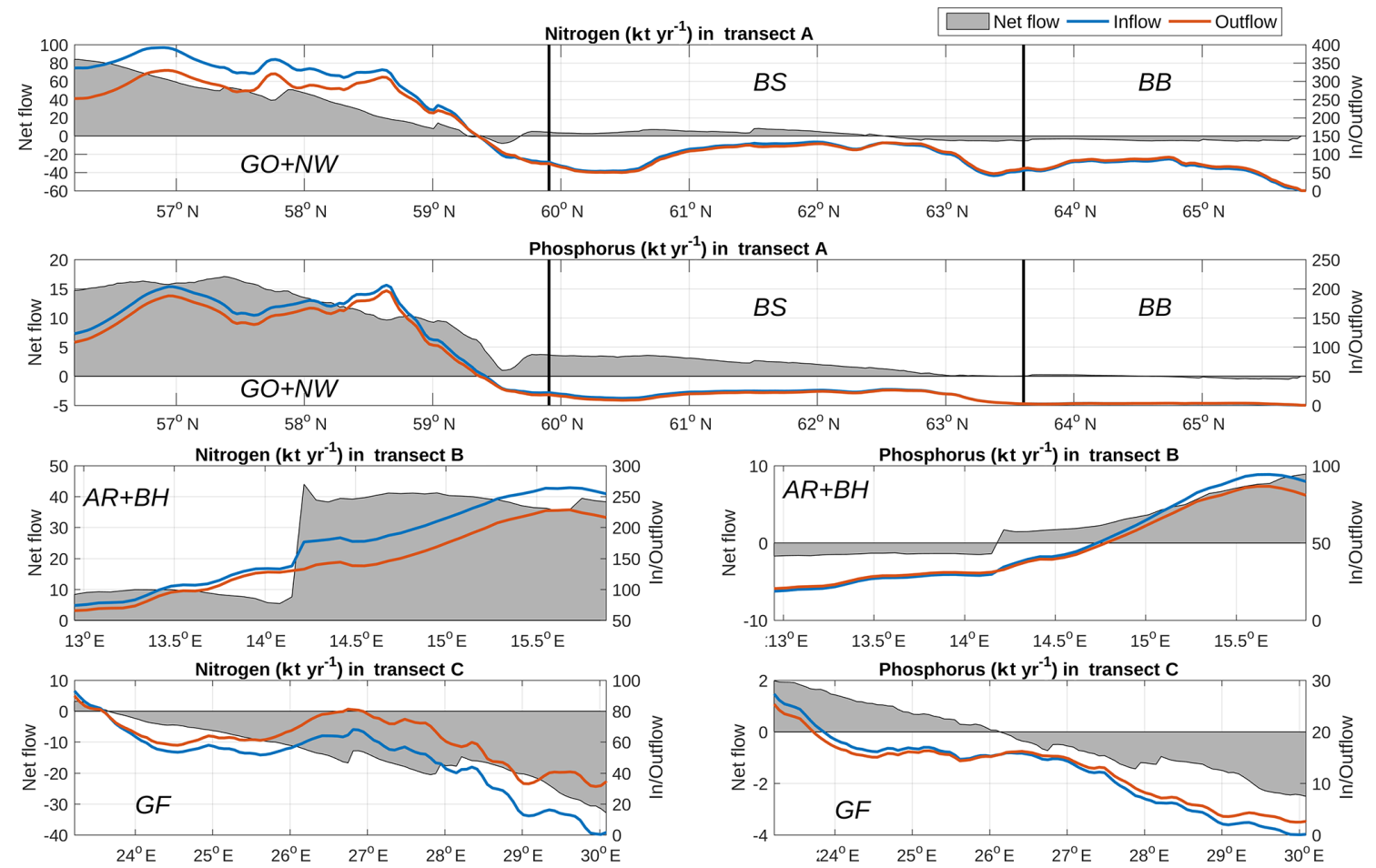

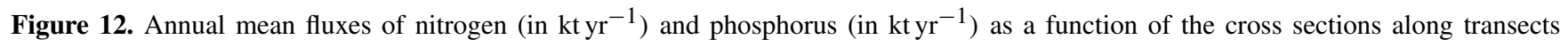
following the latitude and longitude in the Baltic sub-basins. Northward and eastward fluxes are, by definition, positive and called inflows. Southward and westward flows are called outflows. Net flow is the difference between in- and outflows. Here, AR, BH, GO, NW, GF, BS and BB represent the Arkona Sea, Bornholm Sea, eastern Gotland Basin, northwestern Gotland Basin, Gulf of Finland, Bothnian Sea and Bothnian Bay, respectively. Transect A summarizes fluxes from the southern Baltic proper to the Bothnian Bay. Transect B describes the Baltic Sea entrance area from the Arkona Basin to the Bornholm Basin and transect C summarizes fluxes in the Gulf of Finland (see Fig. 1).

tal nitrogen pool in the Baltic proper increased from 657 to $1045 \mathrm{kt}$ from the period 1971-1975 to 1995-1999, while the total phosphorus pool decreased from $469 \mathrm{kt}$ to $448 \mathrm{kt}$ between the same periods. Hence, nitrogen increased by about $59 \%$, while phosphorus decreased by about $4 \%$. Similarly the pool of DIN in REANA increased by $80 \%$, while DIP decreased by $6 \%$. The corresponding numbers obtained from BED showed an increase of $100 \%$ for DIN and an increase of $7 \%$ for DIP. The results indicate large increases of nitrogen pools in the Baltic proper during the investigated period but only relatively small changes of phosphorus pools.

Subsequent periodic assessments can be used to reveal future eutrophication changes. While estimating the trophic state, it should be noted that the change in trophic state depends on the chosen time periods. For example, from the year 1971-1999 the total phosphorus (TP) in the Baltic proper increased by $2.7 \mathrm{kt} \mathrm{yr}^{-1}$. This result differs from the decrease seen from the 5-year average change discussed above. The reason is the impact from short-term fluctuations of nutrient content (Fig. 4) that may be larger than the long-term changes.

\subsection{Baltic nutrient flows}

To further analyze the variability of the budget of the reanalyzed nutrients, Fig. 12 provides the cross sectional, integrated nutrient flows in the different sub-basins. Here the eastward and northward net transports are, by definition, positive. Obviously, the integrated nutrient flows vary significantly in space according to the nutrient loads from land. The inflows and outflows also vary depending on the depth of the water column and nutrient concentrations that influence the vertically integrated mass fluxes. In general, the magnitude of nutrient transports declines along transect A from south to north. For instance, the largest annual northward flow of nitrogen in the Baltic proper reaches $392 \mathrm{kt} \mathrm{yr}^{-1}$, while it is only 133 and $87 \mathrm{kt} \mathrm{yr}^{-1}$ for the Bothnian Sea and Bothnian Bay, respectively.

In the Baltic proper, inflow and outflow as well as the net northward flow of phosphorus increase from the south until a section along $56.8^{\circ} \mathrm{N}$; they then remain about constant until a section along $58.7^{\circ} \mathrm{N}$ and thereafter decrease rapidly further to the north. This indicates that major sources are located in the south where the large rivers pour their loads into the Baltic Sea, while the major net sinks are mainly found in the northern parts of the Baltic proper. The behavior of the net 
northward flow of nitrogen is different. Nitrogen transports decrease constantly with increasing latitude because the major sink works differently for nitrogen (i.e., denitrification) than for phosphorus, which is retained mainly by burial in the sediments. The net northward flow decreases at the latitude of the Gulf of Finland where phosphorus (and nitrogen) are transported towards the Gulf, as seen in transect C.

In the Arkona and Bornholm basins, nitrogen and phosphorus transports increase from the west to the east. Due to the nitrogen load from the Oder River, the inflow of nitrogen increases significantly at the border between the Arkona and Bornholm basins, whereas the outflow does not show any discontinuity. As a result, the net flow of nitrogen shows an accelerated increase. The situation for phosphorus in the Arkona and Bornholm basins is different compared to the nitrogen transports because in- and outflow change direction. The phosphorus loads from the Oder River turn the outflow in the western parts into an inflow of phosphorus in the eastern parts.

In the Gulf of Finland, in- and outflows generally decline from the west to east. In the entrance of the Gulf of Finland, the net inflows of nutrients are almost zero. The largest net flow (westward) of nutrients appear at the inner end of the Gulf of Finland, where the large river Neva enters the Gulf, with a magnitude of $33 \mathrm{kt} \mathrm{yr}^{-1}$ for nitrogen and $2.6 \mathrm{kt} \mathrm{yr}^{-1}$ for phosphorus, respectively. The net flows of both phosphorus and nitrogen change their directions in the Gulf of Finland, and for nitrogen this change take place closer to the Baltic proper entrance than for phosphorus. These results indicate that the large supply of nutrients from the Neva River are accumulated or removed within the Gulf of Finland.

\section{Discussion}

\subsection{Biases of FREE}

RCO-SCOBI has been widely used for the Baltic Sea and the model was carefully evaluated using various observational data sets. As any other model, RCO-SCOBI had to be calibrated because many processes including sources and sinks of nutrients are not known in enough detail. Hence, an optimal parameterization of unresolved processes is one of the requirements for the predictive capacity of the model. Further requirements to calculate correct transports and transformation processes in addition to optimized model equations are high-quality atmospheric and riverine forcing data and highquality initial and lateral boundary conditions.

Most of the large biases in FREE are caused by imperfect initial conditions. The reason is that the nutrient pools in the sediments have not been spun-up appropriately. As a consequence, phosphate concentrations in FREE are higher than observed concentrations at all depths. The biases in surface phosphate concentrations between model results and observations can influence the seasonal primary production. In
REANA, however, from the beginning of the experiment, the biases are already significantly reduced during the first year and remain relatively small during the integration compared to FREE. This result indicates a need of new initial conditions of the sediments.

\subsection{Non-conservation in REANA}

In the long-term simulation, the new initial condition for an assimilation cycle differs from the ending ocean state of the last cycle when at that time observations are available. In this sense, the data assimilation introduces sources and sinks of the nutrient cycles by interrupting the model simulation and adjusting the initial conditions. The magnitudes of these artificial sources and sinks are directly related to the biases between model results and observations. Figure 3 shows that the model has large biases during the beginning of the simulation. However, data assimilation has corrected the mismatch between model state and observation to an optimal level during an initial adjustment period. After the adjustment period, the mismatch between model and observation becomes small and the successive adjustment due to data assimilation also becomes small. Further, the adjustment of data assimilation is related to the spatial-temporal coverage of observations. Here we assimilated only observed profiles into the model. After every assimilation cycle, the simulation continues with optimal initial conditions based upon conservation principles. As the equations of RCO-SCOBI have not been changed, masses of all constituents of the model are conserved at least during the simulation between two assimilation occasions.

\subsection{Advantages of data assimilation}

The advantage of the data assimilation is that model variables at any station are very likely more accurate than the model output without data assimilation. For instance, time series of profiles or transports across vertical sections very likely have a smaller bias compared to observations than the corresponding model results without data assimilation. Compared to available observations the information from the model is higher-resolved and homogeneous in space and time. Of course, it is difficult to evaluate the quality of model results at high resolution because independent observational data sets are usually missing. An exceptional effort to utilize independent data was done by Liu et al. (2014), showing that the statement about the added value of data assimilation is true for one available, independent cruise data set at high resolution.

The results of the reanalysis can be used to estimate the water quality and ecological state with high spatial and temporal resolution in regions and during periods when no measurements are available. This supports improved assessments, for example, of eutrophication status indicators as exemplified in Sect. 5.6. Regional and local model studies may 
use the data as initial and boundary conditions. For projections of future climate and for nutrient load abatement scenario simulations the reanalysis has a very high scientific value as a reference data set for the historical period of the climate simulations. The evaluation of the regionalized climate (the statistics of mesoscale variability, e.g., the mean state) during the historical period can be done much more accurately based upon the reanalysis data than with sparse observational data. For instance, it is very difficult to calculate the climatological mean state just from observations that are cast only during the ice-free season of the year. Using a reanalysis as reference data for historical climate is a common method in regional climate studies of the atmosphere. Here we provide a corresponding data set for the ocean to evaluate simulated present-day climate.

Further, nutrient transports across selected cross sections or between vertical layers are calculated from the reanalysis with high resolution and improved accuracy. However, one cannot expect that budgets calculated from the summation of internal fluxes from model results with data assimilation are more accurate, because usually small artificial sources and sinks from the data assimilation are becoming as important as physically and biogeochemically motivated sources and sinks when sums of fluxes are compared. Hence, in Sect. 5.6 we calculated budgets only from external supply, imports and exports and changes in the water pools of nutrients with the aim of comparing the reanalysis results with other studies using only observations. It is perhaps not possible to claim that our budgets are more accurate than budgets that are derived from observations only, despite the higher temporal and spatial resolution in model outputs. However, the advantage of the reanalysis is that measurements are extrapolated in space and time based upon physical principles of the model.

\subsection{Comparison with other assimilation methods}

Fu (2013) estimated the volume and salt transports during the 2003 MBI with a three-dimensional variational data assimilation method (3DVAR) in the Baltic Sea. In the present study, we estimate the impact of the data assimilation based upon the EnOI method, on the net volume and nutrient transports as well as calculate budgets for major sub-basins of the Baltic Sea. The volume transports obtained with different assimilation methods may be different. The sea level in Fu (2013) is kept constant in the assimilation process, while sea level in this study is varying accordingly during the assimilation of temperature and salinity based upon the statistical covariances. The variability of sea level may enhance the barotropic flow, which is one of the reasons for the differences in net volume transport between the results by $\mathrm{Fu}$ (2013) and REANA. However, transports within the sub-basin are also indirectly affected by the interaction of baroclinicity and topography.

\subsection{Comparison with other studies on nutrient budgets}

In contrast to Eilola et al. (2012), in this study areas with DIN export are also found at the southern and eastern coasts as well as at some small local regions in the inner parts of the Baltic proper (Fig. 8). In REANA, the magnitudes of DIP imports and exports are larger than in Eilola at al. (2012), and there is pronounced import of DIP in the western part of the eastern Gotland Basin to regions deeper than $100 \mathrm{~m}$ (Fig. 8) that is not as significant in Eilola et al. (2012). This, and the larger variability of DIN imports and exports, indicates that there is a higher degree of small-scale localized transport and production patterns that are not captured by Eilola et al. (2012). Main sinks of DIN are found in the deeper areas, but significant sinks are also seen in shallow areas and areas with water depths of about $60 \mathrm{~m}$. As the assimilation of salinity observations results in a deeper halocline (Liu et al., 2014), the bottom water in a depth range of $40-70 \mathrm{~m}$ contains higher oxygen concentrations than in the simulation without data assimilation. Hence, in the REANA simulation of this study, more phosphorus is retained in regions with water depth in the range of $40-70 \mathrm{~m}$ than in the simulation by Eilola et al. (2012). The present results show, however, an export contribution from DIN sources in deeper areas (e.g., $60-90 \mathrm{~m}$ depths) that may have been caused by reduced denitrification efficiency of oxidized sediments in the REANA simulation compared to Eilola et al. (2012).

The in- and outflows of phosphorus between the subbasins, except the Gulf of Riga and Gulf of Finland, simulated in REANA are smaller than the results by Wulff and Stigebrandt (1989), Savchuk (2005), and Savchuk and Wulff (2007). However, the net transports of phosphorus are similar between our results and these earlier studies in subbasins except Kattegat and Danish Straits. Moreover, the nitrogen budgets are much lower than the results of earlier studies, especially in the Baltic proper. The earlier studies included transports of organic nutrients assumed not bioavailable, comparably high especially for organic nitrogen, in the Baltic Sea, while the present budgets include only biologically active nutrients. This may explain much of the differences in nitrogen transports. It should be kept in mind that the above-mentioned studies estimated the nutrient budgets from mass balance models together with inter-basin transport calculations based upon Knudsen's formula to calculate nutrient budgets of the Baltic Sea (see, e.g., Savchuk, 2005). Obviously, there are limitations in calculations of previous studies. Despite overall uncertainties that also limit the reliability of our results, like incomplete understanding of selected biogeochemical processes (e.g., nitrogen fixation), lacking information of sediment parameters and under-sampled observations in space and time, our approach has the advantage of using both high-resolution modeling and all available observations made over a 30 -year period. Our model results consider the complete set of primitive equations in high resolution, taking into account not only the volume and salt 
conservation of sub-basins according to Knudsen's formula, but also the wind-driven circulation between and within subbasins. Hence, we have, for the first time, the potential to quantify spatial transport patterns with high confidence even within sub-basins, as in the exchange of nutrients between the coastal zone and the open sea.

Eutrophication of the Baltic Sea is directly affected by the long-term evolution of external nutrient supply that has three components (waterborne land loads, direct point sources at the coasts and atmospheric depositions) which are associated with the biogeochemical dynamics of the Baltic Sea. In our study, we used the reconstructed external nutrient input data by Savchuk et al. (2012). Nutrient budgets (Figs. 10 and 11) of sub-basins are time-averaged and represent in our study the overall results of the period 1971-1999. The phosphorus loads vary in different periods, for example, the phosphorus loads in the 1980s are larger relative to the 1990s (see Savchuk et al., 2012). Therefore, the phosphorus supply into the Gulf of Finland is greater in our study compared to Savchuk and Wulff (2007). The greater phosphorus supply changes the phosphorus content and phosphorus concentration in the Gulf of Finland. This is one reason why phosphorus transports between the Gulf of Finland and the Baltic proper in our study are greater than the transports calculated by Savchuk (2005) and Savchuk and Wulff (2007).

Since our study covers a different time period compared to the studies by Wulff and Stigebrandt (1989), Savchuk (2005), and Savchuk and Wulff (2007), nutrient concentrations and related budgets differ in time and space. Hence, it is not surprising that other studies show deviating results. For example, during the period 1970-1999, HELCOM (2013) showed that the TP concentration generally decreased in the Bothnian Bay and has increased in the Gulf of Riga. However, these changes in TP concentrations were not monotonous. For example, the TP concentration obviously increased during the period 1970-1976 in the Bothnian Bay. While in the Bothnian Sea, TP concentration increased during the period 1970-1983 and decreased during the period 1990-1999. Similarly, changes in total nitrogen concentration differed during different periods.

Gustafsson et al. (2012) used a process-oriented model that resolves the Baltic Sea spatially in 13 dynamically interconnected and horizontally integrated sub-basins with high vertical resolution to reconstruct the temporal evolution of eutrophication for 1850-2006. Savchuk (2005) and Savchuk and Wulff (2007) applied mass balance models as mentioned above to calculate nutrient budgets of the Baltic Sea. The results of all these models depend on the locations of the subbasin borders which are chosen as far as possible according to dynamical constraints such as sills or fronts that are parameterized to obtain estimates of the water exchanges. Using a high-resolution circulation model, we showed that nutrient flows within the sub-basins may vary considerably (Fig. 12). For instance, we found east- and westward net transports of nitrogen between the Baltic proper and Gulf of Finland de- pending on border locations at 23.2 and $24.0^{\circ} \mathrm{E}$, respectively. The importance of regional variations of sources and sinks for nutrients on the calculation of transports between subbasins therefore seems to be significant and needs to be further studied. Given the uncertainty caused by data assimilation in the present study, we must, however, save the detailed studies of these issues for future work where the artificial impact of data assimilation on sources and sinks will be traced and quantified during the run.

\section{Summary and conclusion}

For the first time, a multi-decadal, high-resolution reanalysis of physical (temperature and salinity) and biogeochemical variables (oxygen, nitrate, phosphate and ammonium) for the Baltic Sea was presented. The reanalysis covers the period 1970-1999. A weakly coupled assimilation scheme using the EnOI method was used to assimilate all available physical and biogeochemical observations into a high-resolution circulation model of the Baltic Sea.

Both assimilated and independent observations collected from different databases were used to evaluate the reanalysis results (REANA). Based on the model-data comparison presented in this study, we found that the model results without data assimilation (FREE) exhibit significant biases in both oxygen and nutrients. The reasons for these biases are not totally understood yet, although it is speculated that the main reasons might be related to the imperfect initial conditions, limitations of model parameterizations, the inaccurate halocline position and, correspondingly, the hypoxic volume (Liu et al., 2014). Based on the calculation of the overall RMSD of oxygen and nutrient concentrations between model results and not-yet-assimilated observations, the results in REANA are considerably better than those in FREE. The total RMSD of the oxygen, nitrate, phosphate and ammonium is reduced respectively by $0.84 \mathrm{mLL}^{-1}$, $0.99 \mathrm{mmol} \mathrm{m}^{-3}, 0.88 \mathrm{mmol} \mathrm{m}^{-3}$ and $0.52 \mathrm{mmol} \mathrm{m}^{-3}$. This means that the overall qualities of simulated oxygen, nitrate, phosphate and ammonium concentrations are improved by $59,46,78$ and $45 \%$, respectively. These results demonstrate the strength of the applied assimilation scheme.

The observation information entering the model affects the oxygen-dependent dynamics of biogeochemical transports significantly due to improved simulation of both physical (e.g., vertical stratification) and biogeochemical parameters (e.g., nutrient concentrations). As examples, we presented improved results of mean seasonal cycles of nutrients and of spatial surface distributions of DIN, DIP and DIN : DIP of the entire Baltic Sea.

Based on the reanalysis simulation, we analyzed nutrient transports in the Baltic Sea. We found that vertically integrated nutrient transports follow the general horizontal water circulation and vary spatially to a large extent. In particular, large nutrient transports were found in the eastern Gotland 
Basin, in the Bornholm Basin, in the Slupsk Channel and in the northwestern Gotland Basin. The persistence of nutrient transports is greater in the eastern and southern than in the northern and western Baltic Sea.

The horizontal distributions of sources and sinks of inorganic and organic nutrients show large spatial variations and may be partly explained by (1) the external supply of nutrients from land, (2) the topographically controlled horizontal nutrient exchange between sub-basins and between the coastal zone and the open sea and (3) vertical stratification that determines redox conditions at the sea floor. The latter is important for the sediment-water fluxes of nutrients and, consequently, for burial of nutrients in the sediments. The reanalysis results suggest that in the Baltic proper, in most areas with a water depth less than the depth of the permanent halocline at about 70-80 m, DIP is imported and transformed either to $\operatorname{OrgP}$ or buried in the sediments in water depths greater than the wave-induced zone at $40-70 \mathrm{~m}$. Whether the latter is an artifact of the assimilation method or a real sink is unclear. On the other hand, in areas with greater water depth, DIP is exported (e.g., released from the sediments under anoxic conditions). Overall, the Baltic proper exports DIP to neighboring sub-basins.

Nitrogen transports are very different compared to phosphorus transports. The shallow coastal zone with water depths less than $10 \mathrm{~m}$ plays an outstanding role for DIN, because within it, large exports occur due to supplies from land. The high productivity in the shallow areas effectively transfers DIN to OrgN, and denitrification decreases the exports of nitrogen from coastal areas to the deeper areas. Most of the exported DIN is removed in shallow waters, while at greater depths imports and exports of DIN are much smaller, indicating the important role of the coastal zone for nitrogen removal.

Detailed nitrogen and phosphorus budgets suggest that nutrient transports in the various sub-basins are controlled by different processes and show different responses to external loads and internal sources and sinks. In particular, the Baltic proper is the sub-basin with the largest nutrient exchanges with its surrounding sub-basins. The Baltic proper exports phosphorus to all sub-basins except the Gulf of Riga. Similarly, the Baltic proper also exports nitrogen to all subbasins except to the Gulf of Riga and Danish Straits. In this sub-basin, the largest internal sink of all sub-basins was also found. The relatively large net export of phosphorus from the Baltic proper into the Bothnian Sea is noteworthy. This finding is in agreement with previous studies. For the budgets of the sub-basins, the location of the lateral borders of the subbasins is important, because net transports may change sign with the location of the border. For instance, in the entrance of the Gulf of Finland, the net phosphorus transport from the Baltic proper is directed eastward but changes direction at about $26^{\circ}$ E. Further to the east, the net phosphorus transport is directed westward.
Data availability. The data sets used in this study can be obtained from the corresponding author (ye.liu@smhi.se).

Competing interests. The authors declare that they have no conflict of interest.

Acknowledgements. The research presented in this study is part of the Baltic Earth programme (Earth System Science for the Baltic Sea region, see http://www.baltic.earth) and was funded by the Swedish Research Council for Environment, Agricultural Sciences and Spatial Planning (FORMAS) within the projects "Impact of accelerated future global mean sea level rise on the phosphorus cycle in the Baltic Sea" (grant no. 214-2009-577), "Impact of changing climate on circulation and biogeochemical cycles of the integrated North Sea and Baltic Sea system" (grant no. 214-2010-1575), and "Estimating nitrogen fixation in past and future climates of the Baltic Sea" (grant no. 214-2013-1449), as well as by the Swedish Research Council within the project "Reconstructing and projecting Baltic Sea climate variability 1850-2100" (grant no. 2012-2017). We thank Dr. Oleg Savchuk (Stockholm University) and one anonymous reviewer for their valuable comments that helped improve the manuscript considerably.

Edited by: E. Marañón

Reviewed by: O. P. Savchuk and one anonymous referee

\section{References}

Allen, J. I., Eknes, M., and Evensen, G.: An Ensemble Kalman Filter with a complex marine ecosystem model: hindcasting phytoplankton in the Cretan Sea, Ann. Geophys., 21, 399-411, doi:10.5194/angeo-21-399-2003, 2003.

Almroth-Rosell, E., Eilola, K., Hordoir, R., Meier, H. E. M., and Hall, P.: Transport of fresh and resuspended particulate organic material in the Baltic Sea - a model study, J. Mar. Sys., 87, 1-12, 2011.

Almroth-Rosell, E., Eilola, K., Kuznetsov, I., Hall, P., and Meier, H. E. M.: A new approach to model oxygen dependent benthic phosphate fluxes in the Baltic Sea, J. Mar. Syst., 144, 127-141, 2015.

Andersen, J. H., Carstensen, J., Conley, D. J., Dromph, K., FlemingLehtinen, V., Gustafsson, B. G., Josefson, A. B., Norkko, A., Villnäs, A., and Murray, C.: Long-term temporal and spatial trends in eutrophication status of the Baltic Sea, Biol. Rev., 92, 135-149, doi:10.1111/brv.12221, 2015.

Béal, D., Brasseur, P., Brankart, J.-M., Ourmières, Y., and Verron, J.: Characterization of mixing errors in a coupled physical biogeochemical model of the North Atlantic: implications for nonlinear estimation using Gaussian anamorphosis, Ocean Sci., 6, 247-262, doi:10.5194/os-6-247-2010, 2010.

Beckmann, A. and Döscher, R.: A method for improved representation of dens water spreading over topography in geopotentialcorrdinate models, J. Phys. Oceanogr., 27, 581-591, 1997

Bengtsson, L., Hodges, K., and Hagemann, S.: Can Climate Trends be calculated from Re-Analysis Data?, J. Geophys. Res., 109, D11111, doi:10.1029/2004JD004536, 2004. 
Bergström, S. and Carlsson, B.: River runoff to the Baltic Sea: 1950-1990, Ambio, 23, 280-287, 1994.

Boesch, D., Hecky, R., O’Melia, C., Schindler, D., and Seitzinger, S.: Eutrophication of seas along Sweden's West Coast, Report No. 5898, Swedish Environmental Protection Agency, p. 78, 2008.

Carton, J. A., Giese, B. S., and Grodsky, S. A.: Sea level rise and the warming of the oceans in the SODA ocean reanalysis, J. Geophys. Res., 110, C09006, doi:10.1029/2004JC002817, 2005.

Ciavatta, S., Kay, S., Saux-Picart, S., Butenschön, M., and Allen, J. I.: Decadal reanalysis of biogeochemical indicators and fluxes in the North West European shelf-sea ecosystem, J. Geophys. ResOceans, 121, 1824-1845, 2016.

Claustre H., Antoine D., Boehme L., Boss E., D’Ortenzio F., Fanton D’Andon, O., Guinet, C., Gruber, N., Handegard, N.O., Hood, M., Johnson, K., Körtzinger, A., Lampitt, R., LeTraon, P.-Y., Lequéré, C., Lewis, M., Perry, M.-J., Platt, T., Roemmich, D., Sathyendranath, S., Testor, P., Send, U., and Yoder, J.: Guidelines Towards an Integrated Ocean Observation System for Ecosystems and Biogeochemical Cycles, Proceedings of OceanObs'09: Sustained Ocean Observations and Information for Society (Vol. 1), Venice, Italy, 21-25 September 2009, edited by: Hall, J., Harrison, D. E., and Stammer, D., ESA Publication WPP-306, doi:10.5270/OceanObs09,14 pp., 2010.

Conley, D. J., Björck, S., Bonsdorff, E., Carstensen, J., Destouni, G., Gustafsson, B. G., Hietanen, S., Kortekaas, M., Kuosa, H., Meier, H. E. M., Múller-Karulis, B., Nordberg, K., Norkko, A., Nưrnberg, G., Pitkänen, H., Rabalais, N. N., Rosenberg, R., Savchuk, O. P., Slomp, C. P., Voss, M., Wulff, F., and Zillén, L.: Hypoxiarelated processes in the Baltic Sea. Critical review, Environ. Sci. Technol., 43, 3412-3420, 2009.

Daewel, U. and Schrum, C.: Simulating long-term dynamics of the coupled North Sea and Baltic Sea ecosystem with ECOSMO II: model description and validation, J. Mar. Syst., 119/120, 30-49, 2013.

Eilola, K., Almroth-Rosell, E., Dieterich, C., Fransner, F., Höglund, A., and Meier, H. E. M.: Modeling nutrient transports and exchanges of nutrients between shallow regions and the open Baltic Sea in present and future climate, Ambio, 41, 574-585, 2012.

Eilola, K., Meier, H. E. M., and Almroth, E.: On the dynamics of oxygen, phosphorus and cyanobacteria in the Baltic Sea: a model study, J. Mar. Syst., 75, 163-184, 2009.

Eilola, K., Gustafson, B. G., Kuznetsov, I., Meier, H. E. M., Neumann, T., and Savchuk, O. P.: Evaluation of biogeochemical cycles in an ensemble of three state-of-the-art numerical models of the Baltic Sea, J. Mar. Syst., 88, 267-284, 2011.

Eilola, K., Mårtensson, S., and Meier, H. E. M.: Modeling the impact of reduced sea ice cover in future climate on the Baltic Sea biogeochemistry, Geophys. Res. Lett., 40, 1-6, 2013.

Eilola, K., Almroth-Rosell, E., and Meier, H. E. M.: Impact of saltwater inflows on phosphorus cycling and eutrophication in the Baltic Sea, A 3D model study, Tellus A, 66, 23985, doi:10.3402/tellusa.v66.23985, 2014.

Fischer, H. and Matthäus, W.: The importance of the Drogden Sill in the Sound for major Baltic inflows, J. Mar. Syst., 9, 137-157, 1996.

Fontana, C., Brasseur, P., and Brankart, J.-M.: Toward a multivariate reanalysis of the North Atlantic Ocean biogeochemistry during
1998-2006 based on the assimilation of SeaWiFS chlorophyll data, Ocean Sci., 9, 37-56, doi:10.5194/os-9-37-2013, 2013.

Friedrichs, M. A. M., Hood, R., and Wiggert, J.: Ecosystem model complexity versus physical forcing: Quantifi cation of their relative impact with assimilated Arabian Sea data, Deep-Sea Res. Pt. II, 53, 576-600, 2006.

Fu, W.: Estimating the volume and salt transports during a major inflow event in the Baltic Sea with the reanalysis of the hydrography based on 3DVAR. J. Geophys. Res.-Ocean., 118, 31033113, 2013.

$\mathrm{Fu}, \mathrm{W} .:$ On the role of temperature and salinity data assimilation to constrain a coupled physical-biogeochemical model in the Baltic Sea, J. Phys. Oceanogr., 46, 713-729, 2016.

Fu, W., She, J., and Dobrynin, M.: A 20-year reanalysis experiment in the Baltic Sea using three-dimensional variational (3DVAR) method, Ocean Sci., 8, 827-844, doi:10.5194/os-8-827-2012, 2012.

Gerdes, R., Köberle, C., and Willebrand, J.: The influence of numerical advection schemes on the results of ocean general circulation models, Clim. Dynam., 5, 211-226, 1991.

Gregg, W. W., Friedrichs, M. A. M., Robinson, A. R., Rose, K. A., Schlitzer, R., Thompson, K. R., and Doney, S.C.: Skill assessment in ocean biological data assimilation, J. Marine Syst., 76, 16-33, 2009.

Gustafsson, B. G., Schenk, F., Blenckner, T., Eilola, K., Meier, H. E. M., Müller-Karulis, B., Neumann, T., Ruoho-Airola, T., Savchuk, O. P., and Zorita, E.: Reconstructing the Development of Baltic Sea Eutrophication 1850-2006, AMBIO, 41, 534-548, 2012.

HELCOM: Approaches and methods for eutrophication target setting in the Baltic Sea region, Balt. Sea Environ. Proc., 133, 7887, 2013.

Hibler, W. D.: A dynamic thermodynamic sea ice model, J. Phys. Oceanogr., 9, 817-846, 1979.

Hoteit, I., Triantafyllou, G., Petihakis, G., and Allen, J. I.: A singular evolutive extended Kalman filter to assimilate real in situ data in a 1-D marine ecosystem model, Ann. Geophys., 21, 389-397, 2003.

Hoteit, I., Triantafyllou, G., and Petihakis, G.: Efficient data assimilation into a complex, 3-D physical-biogeochemical model using partially-local Kalman filters, Ann. Geophys., 23, 3171-3185, 2005.

Hunke, E. C. and Dukowicz, J. K.: An elastic-viscous-plastic model for sea ice dynamics, J. Phys. Oceanogr., 27, 1849-1867, 1997.

Killworth, P. D., Stainforth, D., Webb, D. J., and Paterson S. M.: The development of a free-surface Bryan-Cox-Semtner ocean model, J. Phys. Oceanogr., 21, 1333-1348, 1991.

Lass, H.-U., Prandke, H., and Liljebladh, B.: Dissipation in the Baltic Proper during winter stratification, J. Geophys. Res., 108, 3187, doi:10.1029/2002JC001401, 2003.

Liu, Y., Meier, H. E. M., and Axell, L.: Reanalyzing temperature and salinity on decadal time scales using the ensemble optimal interpolation data assimilation method and a 3-D ocean circulation model of the Baltic Sea, J. Geophys. Res.-Ocean., 118, 5536-5554, 2013.

Liu, Y., Meier, H. E. M., and Eilola, K.: Improving the multiannual, high-resolution modelling of biogeochemical cycles in the Baltic Sea by using data assimilation, Tellus A, 66, 24908, doi:10.3402/tellusa.v66.24908, 2014. 
Maar, M., Møller, E. F., Larsen, J., Madsen, K. S., Wan, Z., She, J., Jonasson, L., and Neumann, T.: Ecosystem modelling across a salinity gradient from the North Sea to the Baltic Sea, Ecol. Model, 222, 1696-1711, 2011.

Marmefelt, E., Arheimer, B., and Langner, J.: An integrated biochemical model system for the Baltic Sea, Hydrobiologia, 393, 45-56, 1999.

Matthäus, W. and Franck, H.: Characteristics of major Baltic inflows - A statistical analysis, Cont. Shelf Res., 12, 1375-1400, 1992.

Meier, H. E. M.: On the parameterization of mixing in threedimensional Baltic Sea models, J. Geophys. Res., 106, 30997 31016, 2001.

Meier, H. E. M.: Modeling the pathways and ages of inflowing salt and freshwater in the Baltic Sea, Estuar. Coast. Shelf Sci., 74, 610-627, 2007

Meier, H. E. M. and Kauker, F.: Sensitivity of the Baltic Sea salinity to the freshwater supply, Clim. Res., 24, 231-242, 2003.

Meier, H. E. M., Döscher, R., and Faxen, T.: A multiprocessor coupled ice-ocean model for the Baltic Sea: Application to the salt inflow, J. Geophys. Res., 108, 3273, doi:10.1029/2000JC000521, 2003.

Meier, H. E. M., Andersson, H. C., Eilola, K., Gustafsson, B. G., Kuznetsov, I., Müller-Karulis, B., Neumann T., and Savchuk, O. P.: Hypoxia in future climates: A model ensemble study for the Baltic Sea, Geophys. Res. Lett., 38, L24608, doi:10.1029/2011GL049929, 2011.

Meier, H. E. M., Andersson, H. C., Dieterich, C., Eilola, K., Gustafsson, B. G., Höglund, A., and Schimanke, S.: Modeling the combined impact of changing climate and changing socioeconomic development on the Baltic Sea environment in an ensemble of transient simulations for 1961-2099, Clim. Dynam., 39, 2421-2441, 2012.

Natvik, L.-J. and Evensen, G.: Assimilation of ocean colour data into a biochemical model of the North Atlantic - Part 1: Data assimilation experiments, J. Marine Syst., 40/41, 127-153, 2003.

Neumann, T., Fennel, W., and Kremp, C.: Experimental simulations with an ecosystem model of the Baltic Sea, Global Biogeochem. Cy., 16, 1-19, 2002.

Orlanski, I.: A simple boundary condition for unbounded hyperbolic flows, J. Comput. Phys., 21, 251-269, 1976.

Pawlak, J. F., Laamanen, M., and Andersen, J. H.: Eutrophication in the Baltic Sea-an integrated thematic assessment of the effects of nutrient enrichment in the Baltic Sea Region, An executive summary, Baltic Sea Environment Proceedings No. 115B, Helsinki Commission (Baltic Marine Environment Protection Commission), 110-116, 2009.

Radtke, H., Neumann, T., Voss, M., and Fennel, W.: Modeling pathways of riverine nitrogen and phosphorus in the Baltic Sea, J. Geophys. Res.-Ocean., 117, C09024, doi:10.1029/2012JC008119, 2012.

Samuelsson, P., Jones, C. G., Willn, U., Ullerstig, A., Golvik, S., Hansson, U., Jansson, C., Kjellström, E., Nikulin, G., and Wyser, K.: The Rossby Centre Regional Climate model RCA3: model description and performance, Tellus A, 63, 4-23, 2011.
Savchuk, O. P.: Resolving the Baltic Sea into seven subbasins: N and P budgets for 1991-1999, J. Mar. Syst., 56, 1-15, 2005.

Savchuk, O. P.: Large-scale dynamics of hypoxia in the Baltic Sea, in: Chemical structure of pelagic redox interfaces: observation and modelling, edited by: Yakushev, E. V., Handbook of environmental chemistry, Berlin, Springer, 24 pp., doi:10.1007/698_2010_53, 2010.

Savchuk, O. P. and Wulff, F.: Modeling the Baltic Sea Eutrophication in a Decision Support System, Ambio, 36, 2-3, 2007.

Savchuk, O. P., Gustafsson, B. G., Rodriguez Medina, M., Sokolov, A.V., and Wulff, F. V.: Nutrient Loads to the Baltic Sea, 19702006, Technical Report, No. 5, Baltic Nest Institute, Stockholm, Sweden, 2012

She, J., Høyer, J. L., and Larsen, J.: Assessment of sea surface temperature observational networks in the Baltic Sea and North Sea, J. Mar. Syst., 65, 314-335, 2007.

Sokolov, A., Andrejev O., Wulff, F., and Rodriguez Medina, M.: The Data Assimilation System for Data Analysis in the Baltic Sea, Systems Ecology Contributions, 3, Stockholm University, 66 pp., 1997.

Stevens, D. P.: The open boundary conditions in the United Kingdom fine-resolution Antarctic model, J. Phys. Oceanogr., 21, 1494-1499, 1991.

Teruzzi, A., Dobricic, S., Solidoro, C., and Cossarini, G.: A 3-D variational assimilation scheme in coupled transportbiogeochemical models: Forecast of Mediterranean biogeochemical properties, J. Geophys. Res.-Ocean., 119, 200-217, 2014.

Triantafyllou, G., Korres, G., Hoteit, I., Petihakis, G., and Banks, A. C.: Assimilation of ocean colour data into a Biogeochemical Flux Model of the Eastern Mediterranean Sea, Ocean Sci., 3, 397-410, doi:10.5194/os-3-397-2007, 2007.

Triantafyllou, G., Hoteit, I., Luo, X., Tsiaras, K., and Petihakis, G.: Assessing a robust ensemble-based Kalman filter for efficient ecosystem data assimilation of the Cretan Sea, J. Mar. Sys., 125, 90-100, 2013.

Väli, G., Meier, H. E. M., and Elken, J.: Simulated halocline variability in the Baltic Sea and its impact on hypoxia during 1961-2007, J. Geophys. Res.-Ocean., 118, 6982-7000, doi:10.1002/2013JC009192, 2013.

Voss, M., Emeis, K.-C., Hille, S., Neumann, T., and Dippner, J. W.: Nitrogen cycle of the Baltic Sea from an isotopic perspective, Global Biogeochem. Cy., 19, GB3001, doi:10.1029/2004GB002338, 2005.

While, J., Totterdell, I., and Martin, M.: Assimilation of $\mathrm{pCO}_{2}$ data into a global coupled physical-biogeochemical ocean model, J. Geophys. Res., 117, C03037, doi:10.1029/2010JC006815, 2012.

Wulff, F. and Stigebrandt, A.: A time-dependent budget model fro nutrients in the Baltic Sea, Global Biogeochem. Cy., 3, 63-78, 1989.

Wulff, F., Rahm, L., and Larsson, P. (Eds.).: A systems analysis of the Baltic Sea: Ecological Studies, Vol. 148, Springer, Berlin, 2001 . 